\title{
Gene expression profiling of Spodoptera frugiperda hemocytes and fat body using cDNA microarray reveals polydnavirus-associated variations in lepidopteran host genes transcript levels M Barat-Houari ${ }^{1}$, F Hilliou ${ }^{2}$, F-X Jousset ${ }^{1}$, L Sofer ${ }^{2}$, E Deleury ${ }^{2}$, J Rocher ${ }^{1}$, M Ravallec ${ }^{1}$, L Galibert ${ }^{1}$, P Delobel ${ }^{3}$, R Feyereisen ${ }^{2}$, P Fournier ${ }^{1}$ and A- N Volkoff*1
}

\author{
Address: ${ }^{1}$ UMR 1231 Biologie Intégrative et Virologie des Insectes. INRA - Université de Montpellier II. Place Eugène Bataillon, Case Courrier 101 \\ 34095 Montpellier Cedex, France, ${ }^{2}$ UMR 1112 R.O.S.E. INRA - Université de Nice-Sophia Antipolis, Laboratoire de Génomique Fonctionnelle \\ des Insectes, 400 route des Chappes, BP 167, 06903 Sophia Antipolis Cedex, France and '3INRA U.M.R. Sciences pour l'Oenologie, Equipe \\ Microbiologie - Bât 28, 2, place Viala, 34060 Montpellier Cedex 01, France \\ Email: M Barat-Houari - mouna.barat@chu-nimes.fr; F Hilliou - hilliou@antibes.inra.fr; F-X Jousset - jousset@ensam.inra.fr; \\ L Sofer - sofer@antibes.inra.fr; E Deleury - deleury@antibes.inra.fr; J Rocher - Janick.Rocher@ema.fr; M Ravallec - ravallec@ensam.inra.fr; \\ L Galibert - galibert@ensam.inra.fr; P Delobel - delobelp@ensam.inra.fr; R Feyereisen - rfeyer@antibes.inra.fr; \\ P Fournier - fourniep@ensam.inra.fr; A-N Volkoff* - volkoff@ensam.inra.fr \\ * Corresponding author
}

Published: 21 June 2006

BMC Genomics 2006, 7:160 doi:10.1186/1471-2164-7-160

This article is available from: http://www.biomedcentral.com/147I-2/64/7//60

(c) 2006 Barat-Houari et al; licensee BioMed Central Ltd.

This is an Open Access article distributed under the terms of the Creative Commons Attribution License (http://creativecommons.org/licenses/by/2.0), which permits unrestricted use, distribution, and reproduction in any medium, provided the original work is properly cited.

\begin{abstract}
Background: Genomic approaches provide unique opportunities to study interactions of insects with their pathogens. We developed a cDNA microarray to analyze the gene transcription profile of the lepidopteran pest Spodoptera frugiperda in response to injection of the polydnavirus HdIV associated with the ichneumonid wasp Hyposoter didymator. Polydnaviruses are associated with parasitic ichneumonoid wasps and are required for their development within the lepidopteran host, in which they act as potent immunosuppressive pathogens. In this study, we analyzed transcriptional variations in the two main effectors of the insect immune response, the hemocytes and the fat body, after injection of filter-purified HdIV.
\end{abstract}

Results: Results show that 24 hours post-injection, about $4 \%$ of the 1750 arrayed host genes display changes in their transcript levels with a large proportion (76\%) showing a decrease. As a comparison, in S. frugiperda fat body, after injection of the pathogenic JcDNV densovirus, 8 genes display significant changes in their transcript level. They differ from the 7 affected by HdIV and, as opposed to HdIV injection, are all up-regulated. Interestingly, several of the genes that are modulated by HdIV injection have been shown to be involved in lepidopteran innate immunity. Levels of transcripts related to calreticulin, prophenoloxidaseactivating enzyme, immulectin-2 and a novel lepidopteran scavenger receptor are decreased in hemocytes of HdIV-injected caterpillars. This was confirmed by quantitative RT-PCR analysis but not observed after injection of heat-inactivated HdIV. Conversely, an increased level of transcripts was found for a galactose-binding lectin and, surprisingly, for the prophenoloxidase subunits. The results obtained suggest that HdIV injection affects transcript levels of genes encoding different components of the host immune response (non-self recognition, humoral and cellular responses).

Conclusion: This analysis of the host-polydnavirus interactions by a microarray approach indicates that the presence of HdIV induces, directly or indirectly, variations in transcript levels of specific host genes, changes that could be responsible in part for the alterations observed in the parasitized host physiology. Development of such global approaches will allow a better understanding of the strategies employed by parasites to manipulate their host physiology, and will permit the identification of potential targets of the immunosuppressive polydnaviruses. 


\section{Background}

Unlike mammals, the defense against microorganisms and foreign organisms in insects relies exclusively on the innate immune response composed of complex and interconnected humoral and cellular mechanisms [1,2]. The humoral response consists of the synthesis of a large variety of antimicrobial peptides (AMPs) mainly by the fat body cells (the equivalent of the liver in mammals) and proteolytic cascades which, upon activation, lead to blood coagulation or melanization [3-6]. Cellular responses include phagocytosis of invading bacteria, apoptotic bodies or small abiotic targets, and the formation of capsules around larger invading intruders such as parasitic wasps' eggs [7]. Lastly, insect antiviral response is still poorly understood but recent studies demonstrate the increasing interest raised by this response [8-10]. The immune response is well known for dipteran insects such as flies and mosquitoes and a large amount of data is also available for lepidopteran insects. In the latter, several AMPs have been characterized. Signal transduction pathways leading to their transcription are probably similar to those of Drosophila, since regulatory motifs such as the kappaBlike and GATA sequences have been identified [11-13] and transcriptional induction by immune challenge has been reported [14]. Pattern recognition proteins such as hemolin, peptidoglycan recognition protein, beta-1,3glucan recognition proteins and immulectins have also been described in lepidopteran insects [15]. Regarding antiviral response within the insect hemocoel in lepidopteran insects, recent studies suggest involvement of humoral effectors such as prophenoloxydase [16] or hemolin [17] and of a cell-mediated response [18]. An increasing number of studies focus on the lepidopteran cellular response and several effectors, including a cytokine-like, receptors or cellular adhesion molecules, have been identified [2,5,19-22]. Encapsulation is a rapid event that results from the activity of hemocytes capable of adhering to invading foreign organisms, the granulocytes and plasmatocytes $[2,22,23]$. In $S$. frugiperda, half an hour after their injection into last instar larvae, hemocytes are already binding to the latex beads (Figure 1A, a). The subsequently recruited hemocytes adhere to the one already spread on the bead in successive layers (Figure 1A, $\mathrm{b}$ and $1 \mathrm{c}$ ) and the capsule, with abundant desmosomelike structures, is complete around most of the beads 8 hours after injection (Figure 1A, d and 1d').

In parasitic wasps, various mechanisms have evolved to circumvent the host immune response and allow successful pre-imaginal development [24-28]. Some species, such as the endoparasitoid wasp Hyposoter didymator from the Ichneumonidae family, utilize endosymbiotic viruses of the Polydnavirus family, characterized by circular segmented DNA genomes, which protect the developing wasp against host defenses. The Hyposoter didymator ichnovirus (HdIV) particles are injected along with the egg into the hemolymph of the lepidopteran host Spodoptera frugiperda larvae. Viral replication occurs exclusively in the calyx of the wasp ovary and high concentrations of viral particles are produced [29]. When introduced into the lepidopteran host hemocoel, HdIV infects several host tissues and the HdIV genes that have been studied to date are rapidly and consistently transcribed [30-33]. Expression of viral genes is associated with phenotypic variations resulting from physiological and developmental alterations in the parasitized larvae, which are required for successful parasitoid development. Among these physiological alterations, HdIV inhibits host humoral and cellular immunity. Indeed, when HdIV is injected 5 hours before or simultaneously with latex beads, the latter are no longer encapsulated (Figure 1B). However, S. frugiperda hemocytes conserve the ability to adhere to the bead and to each other (Figure 1B). HdIV-induced impaired encapsulation is due in part to disruption of the actin cytoskeleton (Volkoff, pers. data), as observed in several other systems $[34,35]$. Another effect of parasitism by polydnavirusassociated wasps is a reduction of prophenoloxidase (proPO) activity and of plasma melanization [36-41]. PO plays a role in cuticle sclerotization, wound healing, and sequestering/killing of invading pathogens (reviewed in [42]). The question as to why it is advantageous for the parasitic wasp or the virus to inhibit proPO activation remains unresolved.

Thus, polydnaviruses are responsible for the disruption of various insect immune components (reviewed in [24]). However, little is known about the precise molecular mechanisms involved. Recent polydnavirus sequencing projects allowed the discovery of a large panel of candidates as virulence or immune suppressive factors, which are encoded by the segmented DNA genomes [43-45]. These polydnavirus genomes, including that of HdIV, encode a family of genes with homology with the Drosophila ankyrin-repeat Cactus protein, the inhibitor of NF$\kappa \mathrm{B}$ in the Toll pathway $[43,46]$. Some of these viral inhibitor kappaB-like proteins have been recently shown to be potent inhibitors of the insect immune system by targeting the NF-кB pathway [47]. With the exception of the viral ankyrins and the viral innexins [48], none of the genes identified until now in the HdIV genome have significant similarities with known genes. Therefore, despite increasing available information on polydnavirus gene sequences, little is known to date about the host cellular targets of the viral gene products. Parasitism often dramatically affects levels of host hemolymph proteins or enzymes (growth-associated proteins such as arylphorin, riboflavin binding hexamer or juvenile hormone esterase, or antibacterial molecules such as lysozyme and cecropin) [49-55]. These changes can be explained by consumption of hemolymph by the parasitoid larva or can arise from 
A
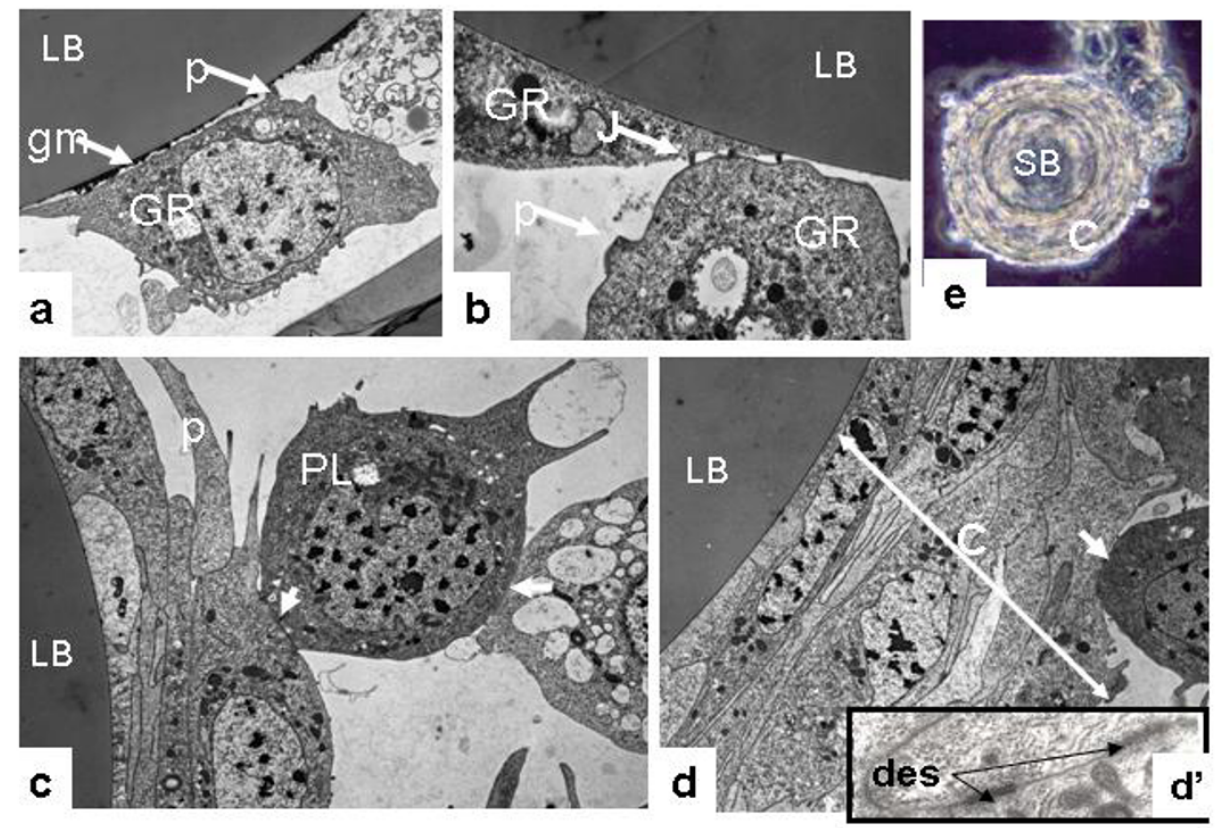

B
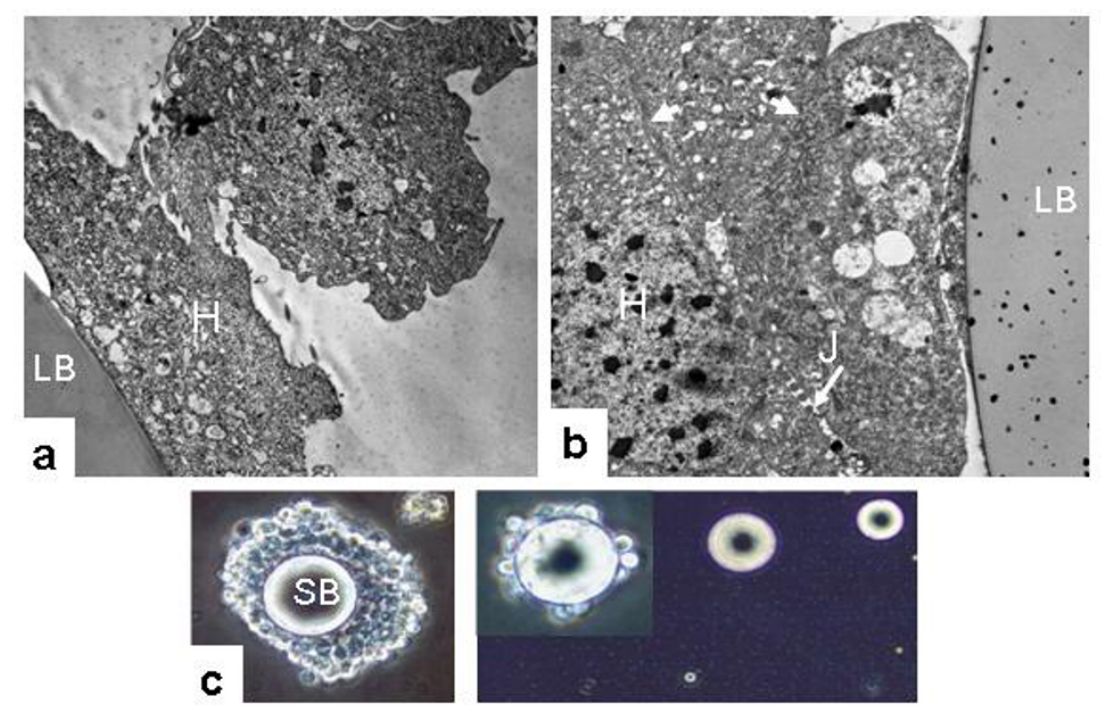

Figure I

Encapsulation of beads in Spodoptera frugiperda last instar larvae. A. Time course of encapsulation, by transmission electronic and photonic observations. a) Bead 30 minutes post-injection (p.i.). Beads are covered by an uncharacterized granular material (as described in Galleria mellonella by Schmit and Ratcliffe [I I5]). b) Bead I hour p.i. c) Bead 2 hours p.i. d) Bead 4 hours p.i. d') Detail showing desmosomes between two cells involved in the capsule. e) Bead 24 hours p.i. (phase contrast observation). B. Effect of injection of HdIV on cellular response. In a) and b) HdIV have been injected 5 hours prior to the beads, in c) HdIV and beads were injected simultaneously. a) Bead 15 hours p.i. b) Bead 6 hours p.i. c) Beads 24 hours p.i. (phase contrast observation). LB: latex bead; C: capsule; gm: granular material; des: desmosome-like junction; H: hemocyte; J: cellular junction; p: pseudopode-like extension; SB: sephadex bead; arrowheads indicate cells already partially attached to each other. The scale bar corresponds to I $\mu \mathrm{m}$ in all views, with exception of Figure Id'), where the scale bar corresponds to $0.5 \mu \mathrm{m}$. 


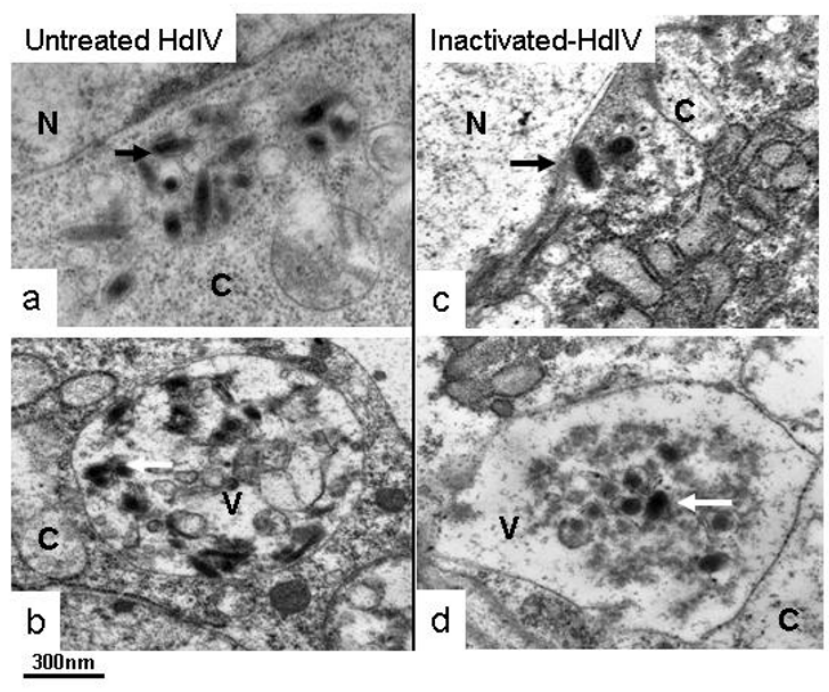

Figure 2

Infection of Spodoptera frugiperda hemocytes after infection of untreated HdIV (left panels, $a$ and $b$ ) and heat-inactivated HdIV (right panels, $c$ and d) by transmission electronic observations. For both control and heat treatment, HdIV particles can be observed within the cytoplasm of hemocytes (black arrows, a and c) and in vacuoles (white arrows, b and d). C: cytoplasm; N: nucleus; V: vacuole.

alterations in levels of gene transcription [51], protein synthesis or other post-transcriptional modifications [49,52-55]. However, reports indicate that gene transcript levels are not changed by polydnavirus infection [53-55] or by calyx fluid injection [51]. Thus, there is no data today that demonstrate regulation of host transcripts by polydnaviruses or calyx fluid.

In insects, microarray approaches have previously been used for analysis of host-pathogen interactions (for example, for Drosophila: [8,56,57]; for Anopheles: [58]) or hostparasite interactions (for Drosophila: [9,59]; for Anopheles: [60]). These studies generally pertain to model insects for which genomic tools are available. However, none of these well-known models are hosts for parasitic wasps associated with polydnaviruses, since this family of viruses is reported only from larval endoparasitoids that develop on lepidopteran hosts, and to our knowledge no such parasitoid attacks the silkworm Bombyx mori, a model lepidopteran with a fully sequenced genome. Thus, because of lack of available tools, such global analyses have not yet been undertaken with lepidopteran species hosting polydnavirus-associated parasitic wasps.

The present study was aimed at investigating by a microarray approach whether HdIV injection induces modifications in the levels of $S$. frugiperda gene transcript levels, resulting either directly from viral gene products or from upstream regulations or feed-back mechanisms. Analysis of the nature of the host genes displaying modified transcript levels, if any, may thus provide clues on the pathways targeted by polydnaviruses and associated factors during parasitism. Moreover, since we are dealing with an immunosuppressive agent, some of those genes may represent new candidate molecules involved in the lepidopteran immune response.

In this study we aimed to establish the gene expression profile of the two main effectors of the $S$. frugiperda immune response, the fat body and the hemocytes, 24 hours after injection of the polydnavirus HdIV. We report in this paper that transcript levels for several host genes are indeed modified in the two immune tissues following HdIV injection. As discussed below, a number of these genes correspond to genes previously shown to be involved in lepidopteran innate immunity.

\section{Results and discussion}

A preliminary construction of four EST libraries for the noctuid pest $S$. frugiperda (EST sequences deposited in the database Spodobase: [61]) allowed us to design a microarray comprising triplicates of $1750 \mathrm{cDNA}$ PCR products printed on glass slides. This CDNA microarray was used to analyze the transcriptional changes in S. frugiperda tissues 24 hours after injection of filter-purified HdIV. At this chosen time point, the HdIV genes studied so far are all transcribed in the lepidopteran host [30-33]. Ten viral cDNAs were spotted on the microarray. Among these genes, four (D8, K29, M24 and P30) displayed significant increases in transcript levels in $S$. frugiperda hemocytes and two (M24 and P30) in the fat body (Additional file 1A). These results were consistent with previous Northern-blot analyses showing high levels of transcripts for these viral genes 24 hours post injection (pi) [30,32].

After microarray analyses, a subset of responsive $S$. frugiperda genes was selected and their transcript levels were analyzed by quantitative RT-PCR 24 hours after injection of heat-inactivated HdIV. Heat inactivation resulted in the absence of viral gene transcription, which was verified by RT-PCR for the viral innexin-1 gene, but did not impair entrance of heat-treated viral particles in host hemocytes (HdIV particles were found in the cytoplasm as well as in vacuoles, similarly to non-heated HdIV; Figure 2). We expected this assay to provide clues whether the observed variations in gene transcript levels were related to HdIV gene transcription or were only the result of the presence of virus particles (recognition).

Moreover, to ascertain that microarray results were relevant to HdIV, and did not merely reflect a global response of the lepidopteran host to the presence of an invader of 
small size such as a virus, we also analyzed the transcriptional profile of $S$. frugiperda fat body 24 hours after injection of the Junonia coenia densovirus (JcDNV). JcDNV is a highly pathogenic non-enveloped virus for $S$. frugiperda larvae that presents a wide range of tissue tropism, including hemocytes and fat body, the latter being the main target organ [62].

\section{General overview of transcriptional profiles in S. frugiperda after injection of HdIV}

As shown in Table 1, 18 genes are significantly up-regulated and 54 genes are significantly down-regulated in $S$. frugiperda hemocytes, 24 hours after injection of filterpurified HdIV. This represents $1.4 \%$ and $3.7 \%$ of the arrayed cDNAs, respectively ( $q$-value $=0.0056$; they correspond to a total of 24 and 65 spots, respectively; see Additional file 1B). The $S$. frugiperda transcripts increase up to 5.9-fold for the up-regulated ones (56\% range from 1.6 to 2.7 and $44 \%$ from 3.0 to 5.9 ), and decrease up to 3.8 -fold for the down-regulated ones (61\% from -1.5 to -1.9 and $39 \%$ from -2.0 to -3.8 ). In the HdIV-infected fat body, using both SAM and GeneAnova analyses, we detected only 7 transcripts $(0.40 \%$ from the overall arrayed cDNAs) that were significantly modulated, all negatively $(q$-value $=0.077)$. Five genes were down-regulated in both hemocytes and fat body (alpha and beta tubulins, enolase, deoxyribose-phosphate aldolase-like and calreticulin; Table 1). Fold changes in fat body are similar to those observed in the hemocytes (up to -2.6). A quantitative RTPCR analysis corroborated the microarray results in HdIVinfected hemocytes and fat body for a subset of 8 genes putatively implicated in insect immunity (Table 2). After injection of heat-inactivated HdIV, 5 out of the 8 analyzed genes did not display any significant changes in their transcript level and 2 varied in the opposite direction when compared to the results of injection of non-inactivated HdIV (galectin and lysozyme; Table 2). These results suggest that for these genes, the variations in transcript level probably resulted from the transcription of HdIV genes.

The transcript levels of 8 genes $(0.51 \%$ of the arrayed cDNAs) displayed a significant increase (up to 5.8-fold) in $S$. frugiperda fat body 24 hours after injection of the densovirus JcDNV. Genes responsive after JcDNV injection differed from those modified after HdIV injection (Table 1). As opposed to HdIV injection, no gene was significantly down-regulated. This result strongly suggests that the transcriptional variations observed in HdIV-injected samples are associated with HdIV rather than merely reflect a response of the lepidopteran host to injection of small foreign invaders such as viruses. However, when the transcript levels of 8 selected genes were analyzed in the hemocytes, we found 2 genes, galectin and immulectin- 2 that were similarly increased and decreased, respectively, by HdIV and JcDNV injection (Table 2). Injection of heat- inactivated HdIV led to a decrease of galectin transcript level and did not affect significantly immulectin (Table 2). This suggests that variations do not reflect $S$. frugiperda response to injection of viral particles but rather that these two genes are targeted by both HdIV and JcDNV.

Thus, both microarray and quantitative RT-PCR results indicate that HdIV injection affects $S$. frugiperda gene transcript levels. Whether these effects are direct or not remains to be further investigated. The expression of the gene encoding the storage protein arylphorin was not affected in our experiments, in agreement with previous reports $[49,54]$. Considering the hemocyte and fat body tissues, $4 \%$ of the arrayed genes displayed modified transcript levels following HdIV injection, the majority (76\%) of them being down-regulated (Table 1). Whereas classical immune challenges cause the majority of the genes to be induced or up-regulated, our finding that genes are essentially down-regulated by HdIV injection was expected, since HdIV represses immune response and development.

\section{Several of the S. frugiperda down-regulated genes 24 hours after injection of HdIV encode proteins related to the immune response}

In the hemocytes, 24 genes (44\% of the down-regulated genes) have either no significant similarity with sequences deposited in databases or similarity with hypothetical proteins of unknown function (classes EII and EIII, as defined in Additional file 2). Based on the hypothesis that host targets for polydnaviruses and associated factors may represent key molecules in lepidopteran physiology, these novel molecules should be further investigated. Of particular interest are those that are prevalent in either one of the hemocyte or fat body libraries. For example two cDNAs that displayed the highest fold changes belong to large clusters in the hemocyte library (Sf1H00035-3-1 and Sf1H02709-3-1, with 19 and 38 clones, respectively, decreased 3.2 and 2.2 fold, respectively).

Among the 56 genes down-regulated in S. frugiperda hemocytes and fat body after HdIV injection, 32 have similarity with known proteins. At least 37\% (12 genes belonging to classes AI, AII, AV, AVI and AIX; Table 1) have presumed ubiquitous functions in cell metabolism, but most of the others are potentially involved in different steps of insect immune responses, as discussed below.

Genes encoding proteins previously described as involved in the insect humoral response

Antimicrobial molecules

Two potential antimicrobial molecules, the cobatoxinlike (decrease 1.98-fold) and a c-type lysozyme (decrease 2.2-fold) have lower transcript levels in hemocytes 24 hours after injection of HdIV compared to injection of 
Table I: List of Spodoptera frugiperda genes transcriptionally modified by HdIV infection.

\begin{tabular}{|c|c|c|c|c|c|c|c|c|c|}
\hline \multirow[t]{2}{*}{ Spodobase ID } & \multirow[t]{2}{*}{ Gene Name } & \multirow[t]{2}{*}{ Functional class } & \multicolumn{4}{|c|}{ Number of clones } & \multirow[t]{2}{*}{ SAM Fold } & \multicolumn{2}{|c|}{ GeneANOVA } \\
\hline & & & $\mathrm{H}$ & $\mathrm{F}$ & M & $\mathrm{L}$ & & $\mathrm{F}_{\text {gene-cond }}^{\circ}$ & P-value \\
\hline \multicolumn{7}{|c|}{ Hemocytes_HdIV : 72 significant genes, 18 up-regulated and 54 down-regulated } & q-value 0.0056 & & \\
\hline SfIH03393-5-I & Fumarate hydratase & AVI tricarboxylic acid cycle & I & 3 & 0 & 0 & 2.24 & 74 & $<0.0000$ I \\
\hline SfIH $00 I 5 I-5-I$ & retinol dehydratase; iso-I & AVI catalytic & 7 & 0 & 0 & 0 & 2.11 & 152 & $<0.00001$ \\
\hline Sf9L0464I I & 90-kDa heat shock protein HSP83 & AVII stress. hsp & 0 & 0 & 2 & 5 & 2.19 & 33 & $<0.0001$ \\
\hline SfIH03026-5-I & heat shock cognate 70 protein & AVII stress. hsp & 1 & 0 & 0 & 0 & 1.58 & 62 & $<0.00001$ \\
\hline SfIH00903-5-I & prefoldin subunit 2 & AVIII processing & 2 & 0 & 1 & 0 & 1.88 & 91 & $<0.00001$ \\
\hline SfIH00522-5-I & Galectin; iso-I & BIII lectin & 3 & 0 & 0 & 0 & 5.66 & 161 & $<0.00001$ \\
\hline SfIHOI648-5-I & Galectin; iso-2 & BIII lectin & 2 & 0 & 0 & 0 & 5.50 & 110 & $<0.00001$ \\
\hline SfIH0I84I-5-I & lectin $(\mathrm{CrV})$ & BIII lectin & 11 & 0 & 0 & 0 & 1.66 & 44 & $<0.0000$ I \\
\hline SfIH03263-5-I & MBF2 & $\mathrm{C}$ regulator & 10 & 3 & 0 & 0 & 2.18 & NS & $<0.0000$ I \\
\hline SfIH00908-5-I & PPO-I (X 4 spots) & DI PPO & 75 & 0 & 0 & 0 & {$[1.9-4.89]$} & {$[27-144]$} & $<0.00001$ \\
\hline SfIH00508-5-I & PPO-2 (X 3 spots) & DI PPO & 60 & 0 & 0 & 0 & [4.02-5.91] & {$[67-104]$} & $<0.00001$ \\
\hline SfIHOI637-5-I & Hypothetical protein A.gambiae & Ell & 1 & 0 & 0 & 0 & 2.73 & 250 & $<0.0000$ I \\
\hline Sf9L0859I & Hypothetical protein Drosophila & Ell & 0 & 0 & 1 & 1 & 2.52 & 96 & $<0.0000$ I \\
\hline SfIH00837-3-I & No Similarity & EIII & 1 & 0 & 0 & 0 & 2.74 & 134 & $<0.00001$ \\
\hline SfIH0087I-5-I & No Similarity & EIII & 1 & 0 & 0 & 0 & 2.98 & 261 & $<0.00001$ \\
\hline SfIHOI434-3-I & No Similarity & EIII & 1 & 0 & 0 & 0 & 3.03 & 102 & $<0.00001$ \\
\hline SfIH02673-5-I & No Similarity & EIII & 1 & 0 & 0 & 0 & 1.96 & 173 & $<0.0000$ I \\
\hline SfIH0020I-3-I & NS. similar to Hypothetical protein (5' seq) & EllI & 2 & 0 & 0 & 0 & 2.73 & 93 & $<0.00001$ \\
\hline SfIH02439-5-I & Annexin IX-B & Al Ca binding & 7 & 3 & 0 & 0 & $0.62(-1.61)$ & 66 & $<0.00001$ \\
\hline Sf9L07393 & Calmodulin & Al Ca binding & 5 & 2 & 11 & 6 & $0.59(-1.69)$ & 31 & $<0.0001$ \\
\hline Sf9L07।35 & Cytochrome C oxydase I & Al electron transport & 162 & 117 & 232 & 146 & $0.62(-1.61)$ & 30 & $<0.0001$ \\
\hline SfIH02665-5-I & splicing factor $3 \mathrm{a}$ & All splicing & 1 & 0 & 0 & 0 & $0.48(-2.08)$ & 196 & $<0.0000$ I \\
\hline Sf9L06869 & cofilin & AIV actin & 16 & 1 & 10 & 2 & $0.54(-1.85)$ & 62 & $<0.00001$ \\
\hline SfIH03446-5-I & profiling & AIV actin & 30 & 2 & 16 & 0 & $0.54(-1.85)$ & 142 & $<0.00001$ \\
\hline Sf9L03392 & Thymosin beta & AIV actin & 7 & 1 & 3 & 13 & $0.45(-2.22)$ & 33 & $<0.0001$ \\
\hline Sf9L06055 & alpha tubulin & AIV tubulin & 5 & 5 & 7 & 7 & $0.56(-1.80)$ & 56 & $<0.0000$ I \\
\hline Sf9L0I568 & beta-I tubulin & AIV tubulin & 1 & 2 & 2 & 1 & $0.56(-1.80)$ & NS & $<0.0000$ I \\
\hline SfIH02495-5-I & synaptotagmin-like; granuphilin & AIX exocytosis & 2 & 0 & 0 & 0 & $0.65(-1.54)$ & 27 & $<0.0001$ \\
\hline Sf9LOI210 & Ribosomal protein S24 & AV ribosomal & 1 & 0 & 4 & 21 & $0.58(-I .7 I)$ & 84 & $<0.0000$ I \\
\hline SfIH02303-5-I & kynurenine aminotransferase & AVI biosynthesis & 2 & 0 & 0 & 0 & $0.60(-1.66)$ & 73 & $<0.00001$ \\
\hline
\end{tabular}


Table I: List of Spodoptera frugiperda genes transcriptionally modified by HdIV infection. (Continued)

\begin{tabular}{|c|c|c|c|c|c|c|c|c|c|}
\hline SfIHOI920-5-I & beta glucosidase; iso-I & AVI carbohydrate metabolism & 1 & 1 & 0 & 0 & $0.58(-1.72)$ & 123 & $<0.00001$ \\
\hline SfIH0I659-5-I & putative carboxylesterase & AVI catalytic & 5 & I & 0 & 0 & $0.56(-1.78)$ & 87 & $<0.00001$ \\
\hline Sf9L07277 & enolase & AVI glycolysis & 4 & I & I & 2 & $0.55(-1.82)$ & NS & $<0.00001$ \\
\hline Sf9L06272 & glyceraldehyde-3-phosphate dehydrogenase & AVI glycolysis & I & 3 & 8 & 3 & $0.63(-1.58)$ & 20.82 & $<0.0001$ \\
\hline Sf9L025I 2 & fructose I 6-bisphosphate aldolase & AVI glycolysis & 0 & 0 & 0 & 1 & $0.64(-1.56)$ & 64.61 & $<0.00001$ \\
\hline Sf9L02319 & Deoxyribose-phosphate aldolase-like & AVI nucleotide metabolism & 0 & 0 & 0 & 2 & $0.64(-1.56)$ & 72 & $<0.00001$ \\
\hline SfIH0OI06-5-I & Scavenger receptor;iso-I (X 2 spots) & BI receptor & 7 & 0 & 0 & 0 & {$[0.32-0.59][-1.69 /-3.11]$} & {$[78-159]$} & $<0.00001$ \\
\hline Sf9L03085 & Cyclophilin 5/peptidyl-propyl isomerase 5 & Bll PPlase & 5 & 4 & 4 & 3 & $0.61(-1.64)$ & 34 & $<0.00001$ \\
\hline Sf9L02900 & similar to RAS suppressor protein I & BII Ras signal transduction & 0 & 0 & 0 & 2 & $0.66(-1.52)$ & 56 & $<0.0000$ I \\
\hline SfIH0I096-5-I & hemicentin (X 3 spots) & BIII CAM & 11 & 0 & 0 & 0 & {$[0.45-0.48][-2.10 /-2.22]$} & {$[117-132]^{*}$} & $<0.00001$ \\
\hline Sf9L074|4 & collagen alpha I (IV) (X 2 spots) & BIII ECM & 0 & 0 & 0 & I & {$[0.27-0.41][-2.44 /-3.70]$} & [63-207] & $<0.00001$ \\
\hline SfIH0I457-5-I & collagen alpha 2 (IV) & BIII ECM & I & 2 & 0 & 0 & $0.45(-2.22)$ & 203 & $<0.00001$ \\
\hline Sf9L06099 & cobatoxin-like protein; iso-I & DI AMP & 0 & 0 & 0 & 2 & $0.50(-1.98)$ & 43 & $<0.00001$ \\
\hline SfIH0II36-5-I & lysozyme (X 2 spots) & DI AMP & 140 & 86 & 18 & 0 & $0.46(-2.17)$ & 114 & $<0.00001$ \\
\hline SfIH00867-5-I & hemocytin precursor & DI lectin & 3 & 0 & 0 & 0 & $0.52(-1.93)$ & 111 & $<0.00001$ \\
\hline SfIH0I505-5-I & immulectin-2 & DI LPS binding & 5 & 0 & 0 & 0 & $0.52(-1.93)$ & 99 & $<0.00001$ \\
\hline Sf9L00974 & calreticulin & DI multi-function & 5 & 1 & 0 & I & $0.51(-1.96)$ & 38 & $<0.00001$ \\
\hline SfIH00566-5-I & PPO activating Enzyme & DI PPAE & 4 & 0 & 0 & 0 & $0.45(-2.22)$ & 196 & $<0.00001$ \\
\hline SfIH02709-3-I & Hypothetical protein A. gambiae (X 5 spots) & Ell & 38 & 0 & 0 & 0 & {$[0.44-0.55][-1.82 /-2.27]$} & {$[88-140]^{*}$} & $<0.00001$ \\
\hline SfIH02044-5-I & Hypothetical protein Drosophila & Ell & 1 & 0 & 0 & 0 & $0.61(-1.64)$ & 137 & $<0.00001$ \\
\hline Sf9L08287 & Hypothetical protein A. gambiae & Ell & 0 & 0 & 0 & 1 & $0.50(-1.99)$ & 47 & $<0.00001$ \\
\hline Sf9L0659I & Hypothetical protein Drosophila & Ell & 0 & 0 & 0 & 1 & $0.57(-1.75)$ & 36 & $<0.00001$ \\
\hline Sf9L06826 & Hypothetical protein Drosophila & Ell & 0 & 0 & 0 & 1 & $0.66(-1.52)$ & 26 & $<0.0001$ \\
\hline Sf9L00I77 & similar to calponin; iso- $\mathrm{I}$ & Ell & 4 & 0 & 0 & 7 & $0.59(-1.69)$ & 31 & $<0.0001$ \\
\hline SfIH0068I-5-I & similar to LPS-induced TNF-alpha factor ( $X 2$ spots) & Ell & 15 & 2 & 0 & I & {$[0.47-0.52][-1.92 /-2.13]$} & {$[123-159]$} & $<0.00001$ \\
\hline SfIH03038-5-I & similar to pancreatic triacylglyceride lipase ( $X 2$ spots) & Ell & 6 & 0 & 0 & 0 & {$[0.45-0.46][-2.17 /-2.22]$} & {$[8|-| 50]$} & $<0.00001$ \\
\hline SfIH0OII5-5-I & similar to protease inhibitor (AC protein); iso-I & Ell & 3 & 0 & 0 & 0 & $0.50(-2.01)$ & $|3|$ & $<0.00001$ \\
\hline Sf9L04444 & similar to Swiprosin & Ell & 3 & 0 & 0 & I & $0.63(-1.58)$ & 25 & $<0.0001$ \\
\hline SfIH00035-3-I & No Similarity & EIII & 19 & 0 & 0 & 0 & $0.31(-3.19)$ & 88 & $<0.00001$ \\
\hline SfIH00499-5-I & No Similarity & EIII & II & 0 & 0 & 0 & $0.60(-1.66)$ & 14 & $<0.001$ \\
\hline SfIH00686-5-I & No Similarity & EIII & 10 & 0 & 0 & 0 & $0.43(-2.33)$ & 105 & $<0.00001$ \\
\hline SfIH030I4-5-I & No Similarity & EllI & 1 & 2 & 0 & 0 & $0.64(-1.56)$ & 178 & $<0.00001$ \\
\hline SfI F00357-5-I & No Similarity & EIII & 1 & 0 & 0 & 0 & $0.59(-1.68)$ & 21 & $<0.0001$ \\
\hline SfIH00037-3-I & No Similarity & EIII & I & 0 & 0 & 0 & $0.56(-1.78)$ & 212 & $<0.00001$ \\
\hline SfIH00879-5-I & No Similarity & EIII & 1 & 0 & 0 & 0 & $0.53(-1.89)$ & 147 & $<0.00001$ \\
\hline SfIH0I542-3-I & No Similarity & EIII & 1 & 0 & 0 & 0 & $0.43(-2.33)$ & 348 & $<0.00001$ \\
\hline
\end{tabular}


Table I: List of Spodoptera frugiperda genes transcriptionally modified by HdIV infection. (Continued)

\begin{tabular}{|c|c|c|c|c|c|c|c|c|c|}
\hline SfIHOI7I2-5-I & No Similarity & EIII & $\mathrm{I}$ & 0 & 0 & 0 & $0.43(-2.33)$ & 106 & $<0.00001$ \\
\hline SfIH02I05-5-I & No Similarity & EIII & I & 0 & 0 & 0 & $0.4 I(-2.44)$ & 163 & $<0.00001$ \\
\hline Sf9L00090 & No Similarity & EIII & I & 0 & 0 & 4 & $0.62(-1.61)$ & 35 & $<0.00001$ \\
\hline Sf9LOII 58 & No Similarity & EIII & 0 & 0 & I & 2 & $0.45(-2.22)$ & 73 & $<0.00001$ \\
\hline Sf9L06863 & No Similarity & EIII & 0 & 0 & 0 & I & $0.53(-1.89)$ & 43 & $<0.00001$ \\
\hline Sf9L08779 & No Similarity & EIII & 0 & 0 & 0 & I & $0.52(-1.91)$ & NS & $<0.00001$ \\
\hline
\end{tabular}

Fat Body_HdIV : 7 significant genes, down-regulated

q-value $\mathbf{0 . 0 7 7}$

\begin{tabular}{|c|c|c|c|c|c|c|c|c|c|}
\hline Sf9L07I98 & cytoplasmic actin A3 & AIV actin & 27 & 6 & 47 & 2 & $0.59(-1.69)$ & 27 & 0.00001 \\
\hline Sf9L06055 & alpha tubulin & AIV tubulin & 5 & 5 & 7 & 7 & $0.45(-2.22)$ & 135 & $<0.00001$ \\
\hline Sf9L0I568 & beta-I tubulin & AIV tubulin & $\mathrm{I}$ & 2 & 2 & I & $0.65(-1.54)$ & 80 & $<0.00001$ \\
\hline Sf9L07277 & enolase & AVI glycolysis & 4 & 1 & 1 & 2 & $0.54(-1.85)$ & 39 & $<0.00001$ \\
\hline Sf9L02319 & Deoxyribose-phosphate aldolase-like & AVI nucleotide metabolism & 0 & 0 & 0 & 2 & $0.5 I(-1.96)$ & 82 & $<0.00001$ \\
\hline Sf9L00974 & calreticulin & DI multi-function & 5 & 1 & 0 & 1 & $0.38(-2.63)$ & 85 & $<0.00001$ \\
\hline SfIF00299-5-I & Hemolymph glycoprotein precursor & DIII unknown & I & 17 & I & 0 & $0.51(-1.96)$ & 33 & $<0.00001$ \\
\hline
\end{tabular}

\section{Fat Body_JcDNV : 8 significant genes, up-regulated}

q-value $\mathbf{0 . 0 5 6}$

\begin{tabular}{|c|c|c|c|c|c|c|c|c|c|}
\hline Sf9L00253 & mRNA export factor binding & All transcription coactivator & 0 & 0 & 0 & 2 & 1.87 & 35 & $<0.000001$ \\
\hline Sf9L07586 & Ribosomal protein S27A & AV ribosomal & 5 & 3 & 8 & 11 & 3.82 & 136 & $<0.000001$ \\
\hline SfIH03263-5-I & MBF2 & C regulator & 10 & 3 & 0 & 0 & 1.54 & 22 & 0.00006 \\
\hline Sf9L06099 & cobatoxin-like protein; iso-I & DI AMP & 0 & 0 & 0 & 2 & 2.12 & 70 & $<0.000001$ \\
\hline SfIH0OI7I-5-I & lysozyme (X 2 spots) & DI AMP & 140 & 86 & 18 & 0 & {$[1.59-1.66]$} & {$[10-20]$} & 0.0001 \\
\hline Sf9L068I2 & immunolectin-A precursor & DI LPS binding & 0 & 1 & 0 & 2 & 5.88 & 137 & $<0.000001$ \\
\hline Sf9L02793 & No Similarity & EllI & 0 & 0 & 0 & I & 5.46 & 212 & $<0.000001$ \\
\hline Sf9L03। 86 & No Similarity & EIII & 2 & 1 & 7 & 21 & 5.42 & 149 & $<0.000001$ \\
\hline
\end{tabular}

List of Spodoptera frugiperda genes for which transcript levels are significantly modified in the hemocytes and in the fat body 24 hours after injection of HdIV, and in the fat body 24 hours after injection of $\mathrm{cDNV}$, as detected by a modified t-test from the SAM package and an ANOVA based microarray analysis, GeneANOVA. Only the genes with a fold change superior or equal to I.5 with both a FDR median and $90^{\text {th }}$ percentiles of $0 \%$ were kept. For each assay, the SAM q-value (the lowest FDR at which the gene is called significant) is given. For each gene, the $F$ value for "gene-condition" and the p-value calculated by GeneANOVA are given. Single genes for which more than one cDNA was spotted on the glass slide are indicated ( $x$ spots), in those cases, only the spot with the best score was kept in the list. Genes are organized according to their functional annotation (see Additional file 2 for legends). Spodobase ID: identity of the arrayed cDNA in the database Spodobase ([6I]); Gene Name: annotation of the sequence after BlastX search against the GenBank nr database; Functional class: classes and subclasses to which the sequences belong to, based on the classification described in Shida et al. [114] for the ascidian Ciona intestinalis (details in Additional file 2); Number of clones: distribution of the cDNA clones corresponding to the given gene with available sequences in the different S. frugiperda cDNA libraries (H:hemocytes; F: fat body; M:midgut; L:Sf9 cell line). For genes represented by at least two cDNAs, we reported the interval [min, max] for the SAM fold change and for the F gene-condition from GeneANOVA analysis. Asterisk (*) indicate that one of the spots was non significant for GeneANOVA (clusters SfIH0I096-5-I and SfIH02709-3-I). The list of additional clones corresponding to each gene is provided in Additional file IB. 
Table 2: Variation in gene transcript levels in response to virus infection measured by quantitative RT-PCR.

\begin{tabular}{|c|c|c|c|c|c|c|c|c|c|c|}
\hline \multirow{4}{*}{$\begin{array}{l}H / F \\
\text { fold }\end{array}$} & \multirow{2}{*}{\multicolumn{2}{|c|}{$\begin{array}{l}\text { Micro-array } \\
\text { Fold (V/C) }\end{array}$}} & \multicolumn{8}{|c|}{ RT-qPCR } \\
\hline & & & \multicolumn{3}{|c|}{ mean No } & \multicolumn{2}{|c|}{ Fold (V/C) } & \multicolumn{2}{|c|}{ mean No } & \multirow{2}{*}{$\begin{array}{c}\text { Fold }(\mathbf{V} / \mathbf{C}) \\
\text { DNV }\end{array}$} \\
\hline & HdIV & DNV & control PBS $(n=24)$ & $\operatorname{HdIV}(\mathrm{n}=18)$ & $\operatorname{HdIV95}(n=18)$ & HdIV & HdIV95 & control Sf $(n=24)$ & $\operatorname{DNV}(\mathrm{n}=18)$ & \\
\hline & fold & fold & $\min$ mean $\max$ & $\min$ mean $\max$ & $\min$ mean $\max$ & fold & fold & $\min$ mean $\max$ & $\min$ mean $\max$ & fold \\
\hline
\end{tabular}

\section{HEMOCYTES}

\begin{tabular}{|c|c|c|c|c|c|c|c|c|c|c|c|c|c|c|c|c|c|c|c|c|c|}
\hline PPO-I & NS & +4.9 & ND & 0,73 & 0,9 & $1, \mathrm{I}$ & 11.7 & 30.1 & 48.5 & 3.8 & 7.1 & 10.5 & +32.0 & +7.6 & 3.5 & 4.7 & 5.9 & 4.5 & 4.7 & 4.9 & NS \\
\hline PPO-2 & 10.7 & +5.9 & ND & 5.3 & 6.1 & 7.0 & 8.7 & 43.8 & 78.9 & 7.1 & 7.9 & 8.7 & +9.8 & NS & 20.5 & 24.3 & 28.1 & 23.7 & 27.0 & 30.3 & NS \\
\hline Galectin & NS & +5.6 & ND & 0.7 & 0.9 & I.I & 3.8 & 8.9 & 14.1 & 0.3 & 0.5 & 0.7 & +10.0 & -1.7 & 0.6 & 0.8 & 0.9 & 4.0 & 4.8 & 5.6 & +6.5 \\
\hline Scavenger $\mathbf{R}$ & 26,0 & -3.1 & ND & 10,6 & II,8 & 13,0 & $\mathrm{I}, 8$ & 4,3 & 7,0 & 8,4 & 9,5 & 10,6 & -2.8 & NS & 22.0 & 25.0 & 27.9 & 21.5 & 24.2 & 26.9 & NS \\
\hline PPAE & 26.7 & -2.2 & ND & 7,0 & 9,1 & 11,2 & $\mathrm{I}, 7$ & 4,3 & 7,0 & 6.5 & 7.2 & 7.8 & -2.11 & NS & 7.3 & 7.9 & 8.5 & 9.2 & 10.5 & 11.8 & NS \\
\hline Immulectin-2 & 66,0 & -1.9 & ND & 22.1 & 26.9 & 31.8 & 2.7 & 6.0 & 9.3 & 20.9 & 25.0 & 29.0 & -4.5 & NS & 20.0 & 25.9 & 31.7 & 3.2 & 7.6 & 12.0 & -3.4 \\
\hline Lysozyme & 4,0 & -2.2 & ND & 36.0 & 46.8 & 57.6 & 8.2 & 18.7 & 29.1 & 55.4 & 79.9 & 104.3 & -2.3 & +1.7 & 22.7 & 31.8 & 40.8 & 32.4 & 44.7 & 57.0 & NS \\
\hline Calreticulin & NS & -2.0 & ND & 5,5 & 7,4 & 9,2 & $\mathrm{I}, \mathrm{I}$ & 2,4 & 3,8 & 3.5 & 5.5 & 7.5 & $-3,0$ & NS & 3.5 & 4.3 & 5.1 & 3.7 & 4.6 & 5.4 & NS \\
\hline
\end{tabular}

\section{FAT BODY}

\begin{tabular}{|c|c|c|c|c|c|c|c|c|c|c|c|c|c|c|c|c|c|c|c|c|c|}
\hline Lysozyme & -- & NS & +1.7 & 9.9 & 11.8 & 13.8 & 10.9 & 11.7 & 12.5 & 39.6 & 86.7 & 133.8 & NS & +7.3 & 33.8 & 35.7 & 37.6 & 45.5 & 56.3 & 67.1 & +1.6 \\
\hline Calreticulin & -- & -2.6 & NS & 6.5 & 7.7 & 8.9 & 2.0 & 2.5 & 2.9 & 6.5 & 7.6 & 8.6 & -2.9 & NS & 4.5 & 5.8 & 7.2 & 4.8 & 5.8 & 6.8 & NS \\
\hline
\end{tabular}

Variations in gene transcript levels measured by quantitative RT-PCR in response to virus infection. Calculated mean of the relative cDNA starting quantity (N0) and consequential fold changes (V/C: virus/control) for selected Spodoptera frugiperda genes in control and virus-infected hemocytes and fat body 24 hours after injection. Minimum and maximum values obtained from the 18 or 24 replicates are given in addition to the mean NO value. For HdIV assays, the control consisted in injection of PBS, for JCDNV (DNV), in injection of healthy S. frugiperda larvae crushed in PBS; HdIV95 corresponds to injections of heat-inactivated HdIV. H/F: ratio of the relative cDNA starting quantity (N0) between hemocytes and fat body in control PBS samples. ND: not done; NS: not significant; fold change threshold at 1.5 for both microarray and quantitative RT-PCR analyses, with FDR median and 90 th percentiles at $0 \%$. 
saline buffer. Conversely, lysozyme mRNA levels are higher 24 hours after injection of heat-inactivated HdIV, as measured by quantitative RT-PCR (Table 2), with higher fold changes in the fat body $(+7.3)$ than in the hemocytes $(+1.7)$. JcDNV injection also results in increased transcript levels in the fat body $(+2.1$ for cobatoxin and +1.7 for lysozyme). Cobatoxin is a cysteine-rich peptide that may be involved in antimicrobial defense [12] whereas lysozyme is a widely distributed ubiquitous enzyme involved in self-defense from bacterial infection [63]. In Drosophila adults, lysozyme genes are up-regulated $24 \mathrm{hrs}$ after protozoan invasion and down-regulated after fungal invasion [9], but transcript levels remain unchanged after microbial infection [56], or infection with a picorna-like virus [9]. In lepidopteran insects, lysozyme genes are induced in both eggs and pre-imaginal instars in response to bacterial injection $[14,37,64,65]$. In $S$. frugiperda, our results indicate that the c-lysozyme mRNA is more abundant in fat body in response to inactivated-HdIV or to JcDNV compared to control. This suggests that transcript levels of this gene increased in response to viral presence. In host-parasitoid models involving polydnaviruses, the activity of host lysozyme is reported to be inhibited by parasitism [37]. In Heliothis virescens parasitized with Campoletis sonorensis, the observed reduced plasma lysozyme activity involves inhibition at a post-transcriptional step [53]. Our study is the first report of a transcriptional regulation of this antimicrobial gene due to polydnavirus presence and expression. Down-regulation could reflect an active way of protecting both parasitoid wasp and virus from host defense.

\section{The pro-PO cascade}

Our results indicate that HdIV down-regulates the proPOactivation system by directly interfering with transcript levels of genes encoding proteins involved in the enzymatic cascade. Indeed, in this study, we found that a $S$. frugiperda sequence (named $S f_{-} P P A E$ ), similar to the Manduca sexta proPO-activating enzyme PAP-1 gene [66], is specifically down-regulated in the hemocytes 24 hours after injection of HdIV particles (-2.2 in microarrays and 2.1 in quantitative RT-PCR). Similarly to the proPO-activating enzymes (PPAE), Sf_PPAE contains a carboxyl-terminal proteinase domain typical of the chymotrypsin family and has an amino-terminal regulatory "clip" domain (reviewed in [67]). Insect PO is synthesized as an active zymogen (proPO), and is activated by proteolytic cleavage, mediated by a proteinase cascade plus additional factors, including immulectins. The PPAEs are the terminal serine proteinases that carry out the proteolysis of the proPO precursor. In M. sexta, transcription of the proPO-activating enzyme PAP-1 gene is up-regulated in hemocytes and fat body in response to a bacterial challenge and down-regulated by treatment with 20-hydroxyecdysone, suggesting that this gene is under the dual control of immune and hormonal signals [68]. Our results show that HdIV infection down-regulates the transcript levels of the gene encoding this proteinase. Conversely, injection of heat-inactivated HdIV or of JcDNV did not affect transcript levels of $S f_{-} P P A E$. Down regulation of the $S f_{-} P P A E$, as well as of the immulectin gene (see below), should thus reduce the efficiency of pro-PO proteolysis, which could be linked to the inhibition of hemolymph melanization observed in HdIV-infected $S$. frugiperda caterpillars.

\section{Genes encoding proteins putatively involved in the insect cellular immune response and/or non-self recognition Immulectin}

Immulectins are C-type lectins specific to Lepidoptera with a unique structure consisting of tandem carbohydrate recognition domains (CRDs). They function as pathogen recognition receptors in the innate immune system by activating proPO in hemolymph [69], and by participating in hemocyte nodule formation [70] and encapsulation $[71,72]$. HdIV infection down-regulates $(-1.9$ in microarrays and -4.5 in quantitative RT-PCR) a $S$. frugiperda gene with high similarity with the $M$. sexta immulectin-2 (AAF91316; Blast $\mathrm{E}$ value $=6 \mathrm{e}-81$ ), which is induced in M. sexta fat body after bacterial challenge [73]. This S. frugiperda immulectin gene (Sf1H01505-5-1) seems to be preferentially transcribed in hemocytes (Table 2, H/F column) thus differing from other immulectin genes generally reported as synthesized in the fat body and secreted in the hemolymph [72]. Four immulectins are known in M. sexta [72], and we identified 3 different cDNAs in the $S$. frugiperda libraries. One of the other immulectins spotted in the microarray (Sf9L06812) is upregulated by JcDNV in the fat body $(+5.9)$, but is not modified by HdIV, suggesting that different immulectin genes may be differentially affected by HdIV. Down-regulation by HdIV of the $S$. frugiperda immulectin-2 homologue could be linked to inhibition of encapsulation observed in parasitized caterpillars. Interestingly, this gene is also down-regulated by JCDNV in the hemocytes (-3.4 in quantitative RT-PCR), suggesting an important immune function of this protein.

\section{Calreticulin}

In fat body, the highest fold change (-2.6 in microarrays and -3.0 in quantitative RT-PCR) was found for the transcripts related to the multifunctional Ca-binding protein calreticulin (CRT). Transcript levels for CRT also decrease in the hemocytes $(-2.0$ in microarrays and -2.9 in quantitative RT-PCR). Conversely, no variation in the number of transcripts was noted after injection of either JcDNV or heat-inactivated HdIV, suggesting that this variation is related to HdIV gene transcription. CRT is a conserved multifunctional $\mathrm{Ca}^{2+}$-binding protein, detected in a large variety of cellular compartments (reviewed in [74]). Intra- 
Table 3: Variation in SR-C gene transcript levels measured by quantitative RT-PCR.

\begin{tabular}{|c|c|c|c|c|c|c|c|c|c|c|c|c|c|}
\hline \multicolumn{7}{|c|}{ HEMOCYTES (100 ng) } & \multicolumn{7}{|c|}{ HEMOCYTES (4 ng) } \\
\hline \multicolumn{6}{|c|}{ mean No } & \multirow{3}{*}{$\begin{array}{c}\text { Fold } \\
\text { B/C }\end{array}$} & \multicolumn{6}{|c|}{ mean No } & \multirow{2}{*}{$\begin{array}{c}\text { Fold } \\
\text { B/C }\end{array}$} \\
\hline \multicolumn{3}{|c|}{ control $(n=9)$} & \multicolumn{3}{|c|}{ beads $(n=9)$} & & \multicolumn{3}{|c|}{ control $(n=9)$} & \multicolumn{3}{|c|}{ beads $(n=9)$} & \\
\hline $\min$ & mean & $\max$ & $\min$ & mean & $\max$ & & $\min$ & mean & $\max$ & $\min$ & mean & $\max$ & \\
\hline 36.1 & 54.6 & 73.1 & 195.3 & 220.5 & 245.7 & +4.0 & 7.8 & 11.6 & 15.3 & 20.9 & 24.6 & 28.2 & +2.1 \\
\hline
\end{tabular}

Variation in SR-C gene transcript levels measured by quantitative RT-PCR in response to injection of Sephadex beads in the hemocyte population collected 6 to 7 hours after injection. Calculated mean of the relative cDNA starting quantity (N0) and consequential fold changes (B/C: beads/ control). Fold change threshold at 1.5 for quantitative RT-PCR analyses, with FDR median and 90 th percentiles at $0 \%$.

cellular CRT functions as a molecular chaperone and also regulates $\mathrm{Ca}^{2+}$ homeostasis [75]. CRT is also found on the cell surface where it may play a role in cellular adhesion and migration [76] or clearance of apoptotic cells [77]. In insects, CRT has several functions, including functions associated with immunity. In Galleria mellonella, CRT protein was detected in the soluble fraction of hemocyte lysate and surrounding DEAE beads thus suggesting that CRT participates in the non-self recognition of early-stage encapsulation response [78]. The role of CRT in lepidopteran cellular response is also suggested by its presence on the surface of Pieris rapae hemocytes during phagocytosis of yeast cells [79]. Recently, a CRT was identified in the venom fluid of the parasitoid wasp Cotesia rubecula and shown to inhibit host hemocytes in vitro spreading [80]. The authors suggest that the wasp CRT functions as an antagonist of host CRT. In the Hyposoter didymator model, the host CRT gene is down-regulated in HdIV-infected larvae, suggesting a different strategy than C. rubecula. The down-regulation of CRT in HdIV-infected $S$. frugiperda larvae occurs in the same range in both hemocytes and fat body and may thus be responsible for the decrease in nonself recognition and encapsulation efficiency.

\section{Scavenger receptor}

One $S$. frugiperda gene that is down-regulated in response to HdIV injection (1.7/3.1-fold decrease for the two spots, Table 1) encodes a protein with significant similarities with Drosophila class C scavenger receptors (SR-C) (blast E value $=5 e-46$ with GenBank:AAW79423). The S. frugiperda gene encodes a predicted transmembrane protein that contains a MAM domain and two tandem complement control protein (CCP) domains. In Drosophila, the functionally characterized SR-C, dSR-CI, is implicated in phagocytosis and MAM and CCP domains are sufficient for binding of bacteria [81]. Scavenger receptors (SRs) are probably also involved in phagocytosis in Lepidoptera. Indeed, adhesion of E. coli on Spodoptera littoralis granular hemocytes is inhibited with polyinosinic acid, a specific ligand of SRs [82]. Since the dSR-CI recognizes a broad range of polyanionic ligands, similarly to the mammalian class A scavenger receptors [83], SR-C may be the SR responsible for the attachment of bacteria to lepidopteran hemocytes. To test the involvement of $S$. frugiperda SR-C in cellular responses other than phagocytosis, we analyzed the transcript levels of this gene after injection of large Sephadex beads. Beads are fully encapsulated 8 hours after injection and a preliminary macroarray analysis has indicated up-regulation of the SR-C gene 6 hours after injection (not detected 1 hour after injection, Volkoff, unpub.). So SR-C transcript levels were analyzed 6-7 hours after injection by quantitative RT-PCR in 2 different technical and biological conditions. Results indicate that SR-C is up-regulated (2.0/4.0-fold increase) in hemocytes after injection of Sephadex beads (Table 3), strongly suggesting that this novel SR-C plays a role in the $S$. frugiperda cellular response against parasites. The SR-C gene is down-regulated only when HdIV genes are transcribed (non significant with heat-inactivated virus and with JcDNV; Table 2). We thus found two opposite effects on SR-C gene transcript levels for the beads and the virus, suggesting that HdIV acts directly on SR-C transcript levels to impair the host cellular response.

\section{Others}

In addition to the three genes discussed above, HdIV injection down-regulates genes encoding proteins potentially involved in hemocytes adhesion and migration. For example, HdIV injection alters transcript levels of the annexin IX-B (decrease 1.6-fold), a calcium binding protein that plays a role in biological important functions such as membrane fusion and control of cell proliferation and differentiation [84]. In Drosophila, annexin IX is an immune responsive gene that is up-regulated in response to bacterial immune challenge [56,57]. Interestingly, a new discovered hemicentin-like gene (Volkoff et al., unpub.), a putative adhesion molecule of unknown function, is down-regulated in infected hemocytes (fold decrease -2.1/-2.2) as well as a transcript encoding a protein with significant similarity with the C-terminal region of the silkworm humoral lectin (hemocytin, -1.9), an adhesive protein related to encapsulation of foreign substances [85].

Polydnavirus, as other immunosuppressive virulence factors, commonly results in disruption of the hemocytes actin cytoskeleton [24]. Microarrays indicate that, besides down-regulating the two tubulin subunits in the hemo- 
cytes and in the fat body, injection of HdIV affects transcripts of several genes encoding proteins involved in actin-based motility processes, such as thymosin $(-2.2)$, profilin $(-1.85)$ and cofilin $(-1.85)$. The reason for the down-regulation of structural cytoskeleton proteins (actin, alpha- and beta-tubulin) in the fat body is not known, and could be related to modifications in cellular trafficking, mitosis, or apoptosis (preparation to pupation). Actin-binding proteins are commonly found as upregulated in genome-wide analyses of immune challenged Drosophila [8,57]. Inhibition of regulatory proteins of the actin cytoskeleton by HdIV is concordant with recent analyses in CsIV-infected hemocytes suggesting that actin is depolymerised or synthesized in lesser amounts [35].

Presence of HdIV also down-regulates genes that encode proteins involved in the assembly of the extracellular matrix, such as type IV collagens, components of basement membranes. Both collagen alpha-1 (2 spots) and collagen alpha- 2 mRNAs were less abundant after injection of HdIV (-2.4/-3.7 and -2.2, respectively). Components of basement membrane are secreted by hemocytes (mainly granulocytes in Lepidoptera) and integrity of the basement membranes seems to play a central role in nonself recognition by hemocytes (reviewed in [2]). Decreased transcripts of collagen in HdIV-infected hemocytes could be related to a less efficient cellular response, although the mechanism remains unclear.

\section{Some S. frugiperda genes display increased transcript level in hemocytes 24 hours after HdIV injection}

Among the 18 genes that are up-regulated in the hemocytes after HdIV injection, 11 encode proteins with similarities with known proteins (Table 1). The highest transcript levels variations were observed for the genes encoding galectin and the prophenoloxidase subunits 1 and 2 (PPO-1 and PPO-2).

\section{Galectin}

Two genes encoding sequences similar to galectins display an important increase of transcript levels 24 hours after HdIV injection in S. frugiperda hemocytes (average of 5.6fold in microarrays and 10.0-fold in quantitative RT-PCR; Table 1). Galectins are thiol-dependent $\beta$-galactosidebinding lectins found in a large variety of organisms (reviewed in [86]). The S. frugiperda galectin gene is specifically transcribed in hemocytes (Barat-Houari, unpub. results) and encodes a protein containing a single carbohydrate recognition domain, which is more similar to the mammalian galectin-9 than to other described insect galectins. The $S$. frugiperda galectin gene is also up-regulated in hemocytes following JcDNV injection (6.5-fold increase), but down-regulated after injection of heat-inactivated HdIV (1.6-fold decrease; Table 2). In vertebrates, galectins are involved in a variety of cellular processes such as adhesion [87], apoptosis [88] and they possibly regulate innate immune responses [86]. In insects, galectins are thought to have dual functions in development and innate immunity (reviewed in [89]). In Anopheles gambiae, two galectin genes, GALE8 and GALE5 are induced by bacterial and malarial challenges [90]. In Drosophila, the Dmgal galectin is expressed in hemocytes and may participate in recognition of microorganisms or, alternatively, modulate hemocyte aggregation during infection [89]. It is possible that increased galectin levels in HdIV-infected S. frugiperda larvae might lead to the abnormal clumping of hemocytes observed in parasitized larvae (Volkoff, pers. data), thus contributing to a reduction in the number of circulating hemocytes capable of forming the capsule, and to a less efficient cellular response $[91,92]$.

\section{Prophenoloxidase subunits}

The two $S$. frugiperda genes encoding the two prophenoloxidase subunits 1 and 2 (PPO- 1 and PPO-2) showed increased transcript levels in microarray experiments. The microarray contains 4 cDNAs encoding the PPO- 1 protein and 3 cDNAs encoding the PPO-2 protein and all of these cDNAs are significantly up-regulated (increases 1.9/4.9fold and 4.0/5.9-fold, respectively; Table 1). This result was confirmed with quantitative RT-PCR on other biological samples (Table 2). The level of transcripts for the proPO-1 gene was still higher after injection of heat-inactivated HdIV (+7.6), suggesting that the up-regulation of this gene is not directly related to HdIV transcription, but could be linked to presence of HdIV in the caterpillar and thus could reflect a response to HdIV presence. The response seems specific to HdIV since, as shown in Table 2 , the transcript level was not changed in caterpillars 24 hours after injection of the densovirus JcDNV. In Drosophila, none of the three proPO genes is induced after microbial infection [56] and enzyme activation does not seem necessary for resistance to microbial infections [93]. Conversely, in mosquito, the expression of two pro-POs is significantly enhanced in response to microfilariae inoculation and blood feeding, respectively [94]. An inducible proPO was identified recently in Spodoptera litura, and its transcript level increases after bacterial infection [95]. Thus the important up-regulation of the two $S$. frugiperda pro-PO genes by HdIV, inactivated or not, may indirectly reflect a response of this insect to enveloped viruses such as HdIV. This would corroborate previous reports on a possible role of $\mathrm{PO}$ in antiviral response in the lepidopteran larvae [16]. We cannot exclude that the highest level of proPO transcripts detected in S. frugiperda hemocytes could also be related to a selective destruction of a subset of hemocytes that are responsible of proPO enzyme production. Indeed, Microplitis demolitor bracovirus (MdBV) selectively induces apoptosis of the granulocytes [96]. However, no clear hemocyte apoptosis is observed after 
infection with HdIV, contrary to this hypothesis. In HdIVinjected $S$. frugiperda larvae, concomitant to increased proPO transcript levels, by 24 hours after HdIV injection, the Sf_PPAE transcript levels have decreased. This should result in a general decrease in $\mathrm{PO}$ activation and in the inhibition of melanisation observed in parasitized caterpillars.

\section{Conclusion}

Polydnavirus or calyx fluid injection was previously reported to affect host protein levels, by inhibiting translation or interfering with post-transcriptional steps in the parasitized host. The transcriptomic analysis of S.frugiperda genes conducted here shows that injection of filterpurified HdIV results in modifications of transcript levels for several host genes. We cannot assert that all the variations detected by this microarray analysis result exclusively from HdIV, but filter purification is a method that minimizes contaminations with wasp proteins [97]. Moreover, results obtained for the genes studied after injection of heat-inactivated HdIV suggest that HdIV transcription is required for the changes observed. Whether the observed variations in host genes transcript levels result from a direct effect of HdIV proteins or from upstream regulations of other genes or proteins in major pathways will need to be further investigated. The foldchanges observed for transcript levels of the down-regulated genes are relatively low (-1.9 in average and maximum -3.7 for collagen in microarray experiment, -3.1 in average and maximum -4.5 for immulectin in quantitative RT-PCR assay), which is consistent with microarray analyses performed in other biological models and for which high fold changes are usually not observed. These results suggest that HdIV infection decreases transcript levels but does not shut-down a large panel of host genes. Moderate and diversified effects on global host physiology at the immune response level as well as at the developmental level are compatible with maintenance and survival of the host during all parasitoid development. Based on our knowledge on other insects, we can conclude that several of the steps in the lepidopteran host immune response are affected. Down-regulation of putative pattern recognition molecules such as calreticulin and immulectin suggests a decreased recognition efficiency of foreign bodies. Decreased levels of transcripts for lysozyme and PPAE indicate that the humoral response is affected. Finally, the cellular response seems to be impaired due to interference with transcript levels of cytoskeleton-related proteins (actin regulatory proteins, tubulins) or scavenger receptors. The next step will be to better characterize these regulated genes at a genomic level, in order to identify common signaling pathways.

This study also raises the question of the function of the proteins encoded by genes affected by the HdIV injection in lepidopteran immune defense and development. Our results suggest an important role for calreticulin, and two novel proteins, scavenger receptor and hemicentin-like proteins, in lepidopteran immune response, and makes lysozyme and PO good candidates as molecules involved in virus recognition and antiviral defense.

Based on the results obtained, we plan now to analyze the interaction between HdIV and the lepidopteran host $S$. frugiperda using a more complete microarray comprising a higher number of probes. This should circumvent the limits of the microarray analysed in this study, particularly the reduced number of genes that were screened. Analyzing the transcript levels of homologues of known components of major pathways involved in insect immune response such as Toll, Imd or Jak/Stat pathways and those of genes previously shown to play a role in the formation of the hemocytic capsule, such as the plasmatocyte spreading peptide cytokine $[98,99]$, or integrins $[19,100]$ or the immunoglobulin domains-containing hemolin (review in [5]), should provide an enhanced outline of the immune-suppressive effects of HdIV.

To conclude, this study, although based on a simplified biological model, provides evidence that infection with the polydnavirus HdIV affects, directly or indirectly, transcript levels of lepidopteran host genes. The results obtained in the present study also validate the transcriptomic approach to analyze the complex interactions in the parasitoid-polydnavirus-host models. Further use of such global approaches should result in a better understanding of the strategies employed by parasites to manipulate their host physiology, and should give new insights on lepidopteran innate immunity by allowing the identification of potential targets of the immunosuppressive polydnaviruses.

\section{Methods}

IIArray design description: construction of Spodoptera frugiperda CDNAs microarrays

The microarrays were glutaraldehyde activated aminosilane-coated glass slides (pre-cleaned gold seal microslides, Merck) on which we spotted in triplicates PCR products corresponding to $S$. frugiperda cDNAs. We used 1750 non-redundant sequences from $4 S$. frugiperda $\mathrm{cDNA}$ libraries (1266 cDNAs from a Sf9 cell line library, 381 from a hemocyte library, 48 from a fat-body library and 55 from a midgut library; sequences available at [61]; [101]) and 11 viral cDNAs as a control.

The DNA probes were amplified by PCR using primers flanking the cDNA inserts, the forward primer 5'-GTGTTGGTACCCGGGAATTCG-3' and the reverse primer 5'GCTCGAGTCTAGAGTCGACTG-3'. These primers had a C6 amine modification in the $5^{\prime}$ end in order to bind to 
the glutaraldehyde activated aminosilane-coated slides. After amplification, the quality of the PCR products was verified by electrophoresis on $0.8 \%$ agarose gels and the DNA purified using QIAquick 96 PCR purification kit (QIAGEN) according to manufacturers' protocol. After quantification using PicoGreen (Molecular Probes), all PCR products were transferred to 384 -well plates, lyophilized and re-suspended in $3 \times$ SSC to a final concentration of $0.150 \mathrm{mg} / \mathrm{ml}$. The spotting was done with a Chip WriterPro spotter (Virtek, Biorad) using PT3000 pins supplied by EBN (Belgium). Each pin withdraws a volume of about 250 nanoliters and deposits a spot volume of about 0.6 nanoliters, with a diameter of approximately 90 to 130 $\mu \mathrm{m}$. The cDNAs were printed on the slides using an element center-center spacing of $180 \mu \mathrm{m}$. After printing, slides were allowed to dry and then used immediately, or were stored desiccated at room temperature. Slides exhibiting defects such as missing or damaged spots were discarded.

Before hybridization, slides were post-processed in several steps as described in Hugot et al. [102] : (a) Unbound DNA was removed by washing with $0.2 \%$ (w/v) SDS and double-distilled water, (b) covalently bound DNA was denatured for $2 \mathrm{~min}$ in boiling water, (c) free aldehydes were reduced by soaking slides for $5 \mathrm{~min}$ in $68 \mathrm{mM}$ sodium borohydride (dissolved in PBS containing 25\% $(\mathrm{v} / \mathrm{v})$ ethanol), and (d) free glasses sites were blocked by an incubation of $30 \mathrm{~min}$ at $60^{\circ} \mathrm{C}$ in the presence of $0.2 \%$ $(\mathrm{w} / \mathrm{v})$ casein. Several washing steps were performed with $0.2 \%(\mathrm{w} / \mathrm{v})$ SDS and double-distilled water. After washes, the post-processed slides were dried by centrifugation at $500 \mathrm{~g}$ for 5 minutes and then either used immediately or stored desiccated at room temperature.

\section{IIIMicroarray experiment description}

I- Experimental design

We performed 2 biological assays, the first with the polydnavirus HdIV and the second with the densovirus JcDNV. Each assay was composed from two sets, named "infected" and "non-infected control", and each set was composed of 201 -day old $S$. frugiperda last instar larvae. For each pair infected/non-infected samples, a second labeling reaction, named dye-swap, was performed with inversion of the fluorescent dyes. For each assay, we prepared 3 independent biological replicates and 2 dye swap per biological replicate, i.e. 6 slides per assay.

\section{2- Sample used, extract preparation and labelling Virus preparation and insect infections}

Hyposoter didymator and S. frugiperda were reared as previously described in Volkoff et al. [29]. HdIV suspension was prepared as previously described [32]. Briefly, ovaries from $40 \mathrm{H}$. didymator females were dissected and dislocated in phosphate-buffered saline (PBS) and then fil- trated with a $0.45 \mu \mathrm{m}$ acetate-cellulose filter. The HdIV suspension obtained was adjusted to $600 \mu \mathrm{l}$ and then each S. frugiperda larva was injected with $27 \mu \mathrm{l}$ (corresponding to 1.8 ovaries/larvae). Each larva from both HdIV-infected and control sets were injected with $27 \mu \mathrm{l}$ of either HdIV suspension or PBS.

We used the densovirus isolated from the lepidopteran Junonia coenia JcDNV [103]. The densoviruses belong to Parvoviridae family and produce highly contagious lethal diseases in invertebrates [62], and Spodoptera species are particularly sensitive to JcDNV. The control and viral inocula were prepared by crushing either healthy or JcDNVinfected S. frugiperda in $1.5 \mathrm{ml}$ of PBS containing $2 \%$ ascorbic acid, $\mathrm{pH}$ 7.2. The homogenates were clarified 10 min at $9000 \mathrm{~g}$, filtrated on a $0.45 \mu \mathrm{m}$ acetate-cellulose filter, and then diluted ten fold. Each larva from the JcDNV infected or control sets were inoculated with $13 \mu \mathrm{l}$ of healthy or viral suspension.

\section{RNA extraction from S. frugiperda tissue samples}

Samples were collected 24 hours post-injection ( $24 \mathrm{~h}$ p.i.) from both virus-infected and non-infected control sets. Total RNA was extracted from tissue samples (hemocytes or fat body cells) using the Rneasy Mini Kit Total RNA according to manufacturers' protocol (Qiagen S.A., Courtaboeuf, France, cat. no. 74106). Hemocytes were collected as previously reported[32]. Dissected fat body was collected directly in the extraction buffer (RLT buffer) from the Rneasy Mini Kit. On-column DNase digestion was then performed with the RNase-free DNase Kit (Qiagen, cat. no. 79254). Additionally, for the JcDNV-infected samples, infection was controlled by RT-PCR using an oligodT primer and a primer specific to the JcDNV viral protein gene.

\section{RT and labeling}

Ten $\mu$ g of total RNA were labeled with either Cy5dCTP or Cy3dCTP using the ChipShot Labeling System (Pronto! ${ }^{\mathrm{TM}}$ Plus System, cat. no. 40054-55, Promega; [104]), according to manufacturers' protocol. We used the dyes from Amersham Biosciences. Non-incorporated dyes were eliminated using the ChipShot Labeling Clean-Up System

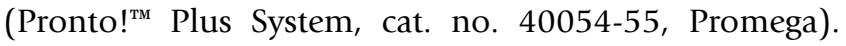
After quantification of each dye incorporation, the labeled cDNAs were dried in speed-vacuum and then dissolved in the required volume of water-diluted Dig Easy hybridization solution (1/3 v/v)(DIG Easy Hyb Granules, Roche Diagnostics GmbH cat. no. 1796 895).

\section{3- Hybridization procedures and parameters}

The labeled cDNAs obtained from the two experimental conditions (i.e. infected and non-infected samples) were mixed in equivalent quantities (pmols) of incorporated Cy3 and Cy5 in order to obtain a final volume of $20 \mu \mathrm{l}$ 
hybridization solution. This solution was then put on the array surface and a micro cover glass $(22 \times 32 \mathrm{~mm})$ was slowly applied to allow the solution spreading and covering the whole spotted area. Slide hybridization was done in Corning CMT-hybridization chambers overnight by total immersion in a water bath at $42^{\circ} \mathrm{C}$, in the dark.

Following overnight hybridization, the slides were washed according to standard procedures [102] and dried by centrifugation at $500 \mathrm{~g}$ for $5 \mathrm{~min}$ before scanning.

\section{4- Data measurement and specifications of data processing Image analysis and quantification}

Hybridized slides were scanned with an Axon 4000 B microarray scanner (Axon Instruments, Foster City, CA) to generate 16-bit TIF images. The laser power was set at $100 \%$ and the photo-multiplier tube (PMT) gain for each wavelength between 600 and 900. Images were analyzed with GenePix Pro4.0 Axon software (adaptative circle segmentation algorithm), according to manufacturers' instructions.

\section{Data standardization and normalization}

After microarray raw data acquisition, data processing was performed using the web-accessible MicroArray Data

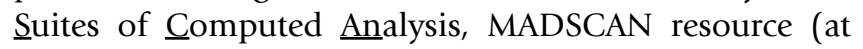
[105]; [106]). The MADSCAN procedure uses the median intensities after background corrections and analytical parameters provided by GenePix Pro. MADSCAN perform physical validation and quality filtration based on fivestep criterion. During these first steps, several spots were ruled out from the analysis. It was the case for viral controls (one JcDNV and HdIV positive controls: rep1, rep2) that displayed poor quality spots and were flagged by the different quality control steps (Genepix or MADSCAN). After data filtration, MADSCAN perform log transformation of the median intensities to makes the distribution of the data symmetrical and almost normal. Hence, the scaled lowess fitness (LOcally-WEighted Regression) normalization algorithm was applied to minimize signaldependent non-linear bias between the two intensity levels. Madscan perform a within-print tip (local) normalization with a smooth parameter (defined as the fraction of data used to smooth at each data point) $f=0.40$ [107].

\section{5- Microarray statistical analysis}

To identify differentially expressed genes, the lowess normalized values of the background corrected intensities obtained from the red and the green channels calculated by MADSCAN were then implemented in two validated statistical analysis programs: the Significant Microarray Analysis (SAM) downloaded from [108] and the GeneAnova program [109]. Only the data significant with the two statistical methods were considered.
For the SAM analysis we kept all the genes with enough non-missing values as program is able to input missed values with the average of the 10 non-missing nearest-neighbor among replicates. We applied the two-class unpaired method from the SAM package to test the null hypothesis of no effect of viral compared to control injection across 18 replicates ( 3 biological $\times 2$ technical dye-swap $\times 3$ within slide as each gene is present in triplicate). This method is a nonparametric test that call significant genes based on the comparison of the experimental score d(i) to its expected value calculated from $\mathrm{N}$ random permutations between treated and untreated sample data (random assignment of treatment). Then, from the randomized data, the SAM program calculates the ratio of the number of false-positives to the expected number of genes called significant. This value provides an estimate of the number of genes identified by chance, the False Discovery Rate (FDR). The $q$-value, calculated from the distribution of the d(i) statistics obtained from permutations, represents the lowest FDR at which the gene is called significant. We selected differentially expressed genes that met both FDR criteria (estimated FDR median and 90th percentiles of $0 \%$ ) and fold change criteria (at least 1.5-fold) [110]). The 1.5 threshold was chosen according to Yang et al. [111], who suggest that fold changes smaller than \pm 2 can reliably identify differentially expressed genes when sufficient number of replicates and flip-dye assays are performed. Afterwards, the results were ascertained with an ANOVA based microarray analysis, GeneANOVA, which is a freely available gene expression analysis of variance software developed by The Laboratory of "Génome et Informatique" at Evry-Génopole [109]. As GeneANOVA requires no missing values, we implemented the program with the SAM imputed data set in which the missed values has been calculated from the mean of 10 non-missing nearest neighbour. For this analysis we constructed a statistical model including 5 factors: genes, type of injection (HdIV versus control or JcDNV versus control), dye label, technical dye-swap replicates and biological replicates. Theses factors represent a set of interacting parameters reflecting differential gene expression across different experimental conditions. ANOVA model allows an estimation of the contribution of each factor from the study design in the total variation of the whole set of measurements and the pair-wise sets of interaction between factors: gene-by-condition, gene-by-slide (i.e. dye-swap technical replicate), gene-by-biological replicate. GeneANOVA gives also the significance of each contribution globally and for each gene. When assessing genes-by-injection interaction, transcriptionally modulated genes identified from the SAM analysis, presented a significant interaction with injection. ANOVA analysis revealed no effect of confounding factors such as dye label and replicates on gene expression levels (i.e. no significant interaction between those factors and injection $\mathrm{p}>0.01$ ), suggesting that the transcriptional 
changes detected by our microarray experiment are independent from dye labeling, technical replicates and biological samples.

\section{III- Quantitative RT-PCR}

The genes retained for real-time quantitative RT-PCR additional investigation, calreticulin, lysozyme, immulectin, the two prophenoloxidases, galectin, scavenger receptor and proPO-activating enzyme, were chosen because of their high fold-change following HdIV infection and their involvement in different immune response mechanisms. All genes were analyzed in hemocytes, a tissue in which all the selected genes, with the exception of calreticulin, are preferentially transcribed (illustrated by the ratio $\mathrm{H} / \mathrm{F}$, Table 2). In the fat body, we restricted analysis for JcDNVregulated gene (lysozyme) and for calreticulin gene, the main fat body HdIV target.

\section{I- Sample preparation}

For real-time quantitative RT-PCR experiments, we repeated the same biological design than what previously described for micro-array assays; a fourth biological replicate was used for control larvae (injected with PBS) in the HdIV assay. Two additional assays were included: an immune challenge assay, and an HdIV-heat inactivation assay.

\section{Immune challenge by injection of beads}

The immune challenge assay consisted in injection of Sephadex beads of 20-50 $\mu \mathrm{m}$ diameter (Sigma G-25) into last instars $S$. frugiperda using an $18 \mathrm{G}$ needle. For kinetics analyses by transmission electron microscopy (TEM), we used latex beads (Sigma SD-91; $90 \mu \mathrm{m}$ diameter). Both latex and Sephadex beads induced an encapsulation response in S. frugiperda larvae. For TEM observations, larvae were dissected in PBS at different times after injection (30 min, 1, 2, 3, 4, 6, 8 and 15 hours) and the beads were individually recovered. For RNA purification, hemolymph containing total hemocytes (circulating hemocytes as well as encapsulated beads) was collected 6 hours or 7 hours after injection.

\section{Inactivation of HdIV}

The aim of the inactivation was to have virus particles susceptible of being recognized by the caterpillar, but no transcription of viral genes. Absence of virus transcription was controlled by RT-PCR using specific primers of the viral innexin-1 gene [48]. Since UV-inactivation did not result in the complete elimination of HdIV transcripts (data not shown), the viral suspension was treated 10 minutes at $95^{\circ} \mathrm{C}$. Integrity of the heat-inactivate virus particles was controlled by negative staining. To verify that heat-inactivate virus particles were still able to infect host tissue, hemocytes collected from 5 injected larvae were observed by TEM. We found a smaller overall amount of virus in the samples, but still found particles within the hemocytes (Figure 2).

\section{2- Transmission electron microscopy (TEM)}

Preparation for TEM observations was identical for hemocytes collected from larvae injected with beads or with HdIV (inactivated or not) and for pelleted encapsulated beads. Cells were pelleted by a gentle centrifugation, washed three times in PBS and fixed with $2 \%(\mathrm{v} / \mathrm{v})$ glutaraldehyde in $0.1 \mathrm{M}$ cacodylate buffer $\mathrm{pH}=7.4$ for overnight at $+4{ }^{\circ} \mathrm{C}$ then post-fixed with $2 \%(\mathrm{v} / \mathrm{v})$ osmium tetroxide in the same buffer for 1 hour at room temperature. Samples were dehydrated through an ethanol series and embedded in Epon. Ultrathin sections contrasted with uranyl acetate and lead citrate were examined under an electron microscope Zeiss EM 10 CR at $80 \mathrm{KV}$.

\section{3- RNA preparation and reverse-transcription}

RNA samples were prepared using Rneasy Mini Kit Total RNA as described above for micro-array assays except an additional step to fully remove cellular and viral genomic DNA. To do this, $8 \mu \mathrm{g}$ of total RNA was incubated at $37^{\circ} \mathrm{C}$ for 3 hours with 8 units Rnase-free RQ1 DNAse (Promega). RNA samples were then ethanol precipitated with sodium acetate, washed twice in $75 \%$ ethanol and resuspended in $8 \mu \mathrm{l}$ of nuclease free water. We controlled the absence of genomic DNA from both cellular and viral origin by subjecting genomic DNA free RNA to two PCRs (1 $\mu \mathrm{g}$ per amplification), firstly to amplify a cellular gene, ELF-1, and secondly a viral specific viral innexin-1 gene. Thus, the $6 \mu \mathrm{g}$ remaining genomic DNA-free total RNA, was reverse transcribed into cDNA using SuperscriptII according to manufacturers' protocol (final volume reaction of $20 \mu \mathrm{l}$ ), to obtain a $0.3 \mu \mathrm{g} / \mu \mathrm{l}$ theoretical concentration of cDNA.

\section{4- Quantitative RT-PCR}

Primer pairs for quantitative RT-PCR for 8 selected genes and 3 endogenous reference genes (Ubiquitin E2, RNA polymerase II and ATP synthase; sequences available in SpodoBase; URL: [61]) were designed using the software package Primer Express $^{\mathrm{TM}}$ from Applied Biosystems, according to the default parameters optimized for the ABI Prism 7000 Sequence Detection System (SDS). Primer sequences and amplicon sizes are available in Additional file 3. For each sample, quantification of gene transcript levels was performed twice in 96-well PCR plates (ABgene). Two different plate designs were obtained by permutation of the plate positions between the whole set of infected and the whole set of non-infected samples. Both plate design comprise triplicate of each biological replicate and were used in two independent quantitative PCR runs. Hence, as for the microarray assays, we analyzed data from a total of 18 replicates at least ( 3 biological replicates $\times 3$ within plate technical replicates $\times 2$ 
technical replicates i.e. repeated measurements) obtained from each real time PCR experiment. The PCR was conducted in a $25 \mu$ l final volume reaction with a PCR mix containing $5 \mu \mathrm{l}$ of cDNA at $4 \mathrm{ng} / \mathrm{ul}$ (i.e. a quantity of cDNA corresponding to $20 \mathrm{ng}$ of total RNA), 1 X PCR buffer (Invitrogen), $3 \mathrm{mM}$ of $\mathrm{MgCl} 2,200 \mu \mathrm{M}$ dNTP mix (Invitrogen), $0.2 \mu \mathrm{l}$ of $1 / 2000$ dilution stock solution of SYBR green I (Invitrogen), $0.5 \mu \mathrm{M}$ of ROX dye (Interchim), $0.4 \mu \mathrm{M}$ of primer pairs and $0.1 \mathrm{U}$ of Platinium Taq DNA polymerase (Invitrogen).

We used the Applied Biosystem 7000 sequence detection system according to the recommended amplification scheme: $95^{\circ} \mathrm{C} 2 \mathrm{~min}$ and 40 cycles: $95^{\circ} \mathrm{C} 15 \mathrm{sec}, 60^{\circ} \mathrm{C} 1$ $\mathrm{min}$. The dissociation curve method was applied according to the manufacturer's protocol $\left(60^{\circ} \mathrm{C}\right.$ to $\left.95^{\circ} \mathrm{C}\right)$ to unsure the presence of a single specific PCR product.

\section{5- Quantitative data analysis}

As other methods for quantitative RT-PCR data analysis are based on the assumption that, for a given amplicon, the PCR efficiency among all individual are similar, we preferred to analyze our data with an assumption-free alternative method. We used the LinReg PCR program developed by Ramakers and coll. [112] that uses the fluorescence of each sample per cycle. This program calculates the starting concentrations of mRNA, which correspond to the intercept of the curve and the slope corresponding to the PCR efficiencies of each individual sample. This analysis uses the Rn values (normalized reporter), which are the fluorescence emission intensity of the reporter dye (SYBRGreen) divided by the Rox passive reference dye intensity. This approach gives the initial number, named NO value, of molecules presents in each sample. Thus, for each of the 8 genes of interest and the 3 endogenous reference genes, the arithmetic mean of NO value was calculated from 6 technical replicates for the 3 or 4 biological replicates. Then, for each tissue and each injection type, we calculated a normalization factor (NF) as described by Vandesompele et al. [113], from the geometric mean of the N0 arithmetic mean obtained for each of the 3 endogenous reference genes from all replicates. The NO arithmetic means from each biological replicate were divided by the corresponding NF (tissue injection) to obtain the relative No values corresponding to the initial transcript level of each gene in a given tissue and condition. Then, normalized NO means were compared between infected and non-infected samples using the SAM program as for microarrays analyses and fold changes were calculated from the quantitative RT-PCR measurements.

\section{Abbreviations}

AMP: antimicrobial peptide

CRT: Calreticulin
HdIV: Hyposoter didymator ichnovirus

JcDNV: Junonia cœnia densonucleosis virus

MAM: $\underline{\text { Meprin, }} \underline{\mathrm{A}} 5$ antigen and receptor protein tyrosine phosphatase $\underline{\text { Mu domain }}$

PO: phenoloxydase

PPAE: prophenoloxidase activating enzyme

SR-C: class C scavenger receptor

TEM: Transmission Electron Microscopy

\section{Authors' contributions}

The study was conducted by M. Barat-Houari, F. Hilliou, F.X. Jousset and A.N. Volkoff, with the help of J. Rocher and L. Galibert; statistical analyses were performed by M. Barat-Houari; M. Ravallec was in charge of electron microscopy preparations; microarrays were spotted by L. Sofer; bioinformatics analysis for microarray construction were conducted by E. Deleury; P. Delobel participated in the scanning and interpretation of microarray results; R. Feyereisen and P. Fournier participated in the study design.

\section{Additional material}

\section{Additional file 1}

Complementary results of microarray analysis. 1 A: Results obtained for the HdIV cDNAs spotted on the microarray. Results obtained for the HdIV $c D N A s$ spotted on the microarray, in the hemocytes $(H)$ and in the fat body (FB) 24 hours after injection of HdIV, as detected by a modified ttest from the SAM package and an ANOVA based microarray analysis, GeneANOVA. Only the genes with a fold change superior or equal to 1.5 with both a "false discovery rate" (FDR) median and $90^{\text {th }}$ percentiles of $0 \%$ were kept. The SAM fold and q-value (the lowest FDR at which the gene is called significant) as well as the ANOVA $F$ "gene-condition" value and the p-value are given. Gene Name: annotation of the sequence. (B) List of additional clones corresponding to each gene. List of additional cDNA clones that have been spotted on the microarray and which corresponded to the same gene.

Click here for file

[http://www.biomedcentral.com/content/supplementary/14712164-7-160-S1.doc]

\section{Additional file 2}

Functional Spodoptera frugiperda gene classification. Functional gene classification based on the one described in Shida et al. for the ascidian Ciona intestinalis [114], and used for the annotation of the Spodoptera frugiperda sequences (Volkoff et al., in prep.).

Click here for file

[http://www.biomedcentral.com/content/supplementary/14712164-7-160-S2.doc] 


\section{Additional file 3}

List of the primers designed for quantitative RT-PCR analysis. List of the forward and reverse primers designed for quantitative RT-PCR analysis of the 8 selected genes and the 3 endogenous reference genes.

Click here for file

[http://www.biomedcentral.com/content/supplementary/14712164-7-160-S3.doc]

\section{Acknowledgements}

The authors thank Bertrand Limier for providing insects, Alessandra Benedetto for help with the statistical analyses, Gilles Didier for providing us the GeneAnova program and Bruno Blondin for access to the Scanning facilities in his laboratory. The authors are grateful to Hélène Volkoff for comments on the manuscript and English revisions.

\section{References}

I. Hoffmann JA: The immune response of Drosophila. Nature 2003, 426(6962):33-38.

2. Lavine MD, Strand MR: Insect hemocytes and their role in immunity. Insect Biochem Mol Biol 2002, 32(10): 1295-1309.

3. Hoffmann JA: Innate immunity of insects. Curr Opin Immunol 1995, 7(I):4-10.

4. Hultmark D: Drosophila immunity: paths and patterns. Curr Opin Immunol 2003, I (I):12-19.

5. Kanost MR, Jiang H, Yu XQ: Innate immune responses of a lepidopteran insect, Manduca sexta. Immunol Rev 2004, 198:97-105.

6. Leclerc V, Reichhart JM: The immune response of Drosophila melanogaster. Immunol Rev 2004, 198:59-7I.

7. Gillespie JP, Kanost MR, Trenczek T: Biological mediators of insect immunity. Annu Rev Entomol 1997, 42:61 I-643.

8. Dostert C, Jouanguy E, Irving P, Troxler L, Galiana-Arnoux D, Hetru C, Hoffmann JA, Imler JL: The Jak-STAT signaling pathway is required but not sufficient for the antiviral response of drosophila. Nat Immunol 2005, 6(9):946-953.

9. Roxstrom-Lindquist K, Terenius $O$, Faye I: Parasite-specific immune response in adult Drosophila melanogaster: a genomic study. EMBO Rep 2004, 5(2):207-2I2.

10. Zambon RA, Nandakumar M, Vakharia VN, Wu LP: The Toll pathway is important for an antiviral response in Drosophila. Proc Natl Acad Sci U S A 2005, I 02(20):7257-7262.

II. Furukawa S, Tanaka H, Nakazawa H, Ishibashi J, Shono T, Yamakawa $\mathrm{M}$ : Inducible gene expression of moricin, a unique antibacterial peptide from the silkworm (Bombyx mori). Biochem J 1999, 340(Pt I):265-27|.

12. Volkoff AN, Rocher J, d'Alencon E, Bouton M, Landais I, QuesadaMoraga E, Vey A, Fournier P, Mita K, Devauchelle G: Characterization and transcriptional profiles of three Spodoptera frugiperda genes encoding cysteine-rich peptides. A new class of defensin-like genes from lepidopteran insects? Gene 2003, 31 9:43-53.

13. Yamakawa M, Tanaka $\mathrm{H}$ : Immune proteins and their gene expression in the silkworm, Bombyx mori. Dev Comp Immunol 1999, 23(4-5):28I-289.

14. Lavine MD, Chen G, Strand MR: Immune challenge differentially affects transcript abundance of three antimicrobial peptides in hemocytes from the moth Pseudoplusia includens. Insect Biochem Mol Biol 2005, 35( I 2): 1335-I346.

15. Yu XQ, Zhu YF, Ma C, Fabrick JA, Kanost MR: Pattern recognition proteins in Manduca sexta plasma. Insect Biochem Mol Biol 2002 32(I0): I 287-I 293.

16. Popham HJ, Shelby KS, Brandt SL, Coudron TA: Potent virucidal activity in larval Heliothis virescens plasma against Helicoverpa zea single capsid nucleopolyhedrovirus. J Gen Virol 2004, 85(Pt 8):2255-226I.

17. Hirai M, Terenius O, Li W, Faye I: Baculovirus and dsRNA induce Hemolin, but no antibacterial activity, in Antheraea pernyi. Insect Mol Biol 2004, I3(4):399-405.
18. Washburn JO, Haas-Stapleton EJ, Tan FF, Beckage NE, Volkman LE: Co-infection of Manduca sexta larvae with polydnavirus from Cotesia congregata increases susceptibility to fatal infection by Autographa californica M Nucleopolyhedrovirus. J Insect Physiol 2000, 46(2): 179-190.

19. Lavine MD, Strand MR: Haemocytes from Pseudoplusia includens express multiple alpha and beta integrin subunits. Insect Mol Biol 2003, I2(5):44I-452.

20. Nardi JB, Zhuang S, Pilas B, Bee CM, Kanost MR: Clustering of adhesion receptors following exposure of insect blood cells to foreign surfaces. Journal Insect Physiology 2005, 5 I (5):555-564.

21. Pech LL, Strand MR: Plasmatocytes from the moth Pseudoplusia includens induce apoptosis of granular cells. J Insect Physiol 2000, 46 (I 2): I 1565-1573.

22. Schmidt $O$, Theopold $U$, Strand M: Innate immunity and its evasion and suppression by hymenopteran endoparasitoids. Bioessays 200I, 23(4):344-35।.

23. Ribeiro C, Brehelin M: Insect haemocytes: What type of cell is that? J Insect Physiol 2006, 52(5):417-429.

24. Glatz RV, Asgari S, Schmidt O: Evolution of polydnaviruses as insect immune suppressors. Trends Microbiol 2004, I 2(1 2):545-554.

25. Labrosse C, Carton Y, Dubuffet A, Drezen JM, Poirie M: Active suppression of $D$. melanogaster immune response by long gland products of the parasitic wasp Leptopilina boulardi. J Insect Physiol 2003, 49(5):5।3-522.

26. Labrosse C, Eslin P, Doury G, Drezen JM, Poirie M: Haemocyte changes in $D$. melanogaster in response to long gland components of the parasitoid wasp Leptopilina boulardi: a RhoGAP protein as an important factor. J Insect Physiol 2005, 5 I(2): $16|-| 70$.

27. Labrosse C, Stasiak K, Lesobre J, Grangeia A, Huguet E, Drezen JM, Poirie M: A RhoGAP protein as a main immune suppressive factor in the Leptopilina boulardi (Hymenoptera, Figitidae)Drosophila melanogaster interaction. Insect Biochem Mol Biol 2005, 35(2):93-103.

28. Pennacchio F, Strand MR: Evolution of developmental strategies in parasitic hymenoptera. Annu Rev Entomol 2006, 5 I :233-258.

29. Volkoff AN, Ravallec M, Bossy JP, Cerutti P, Rocher J, Cerutti M, Devauchelle G: The replication of Hyposoter didymator polydnavirus: Cytopathology of the calyx cells in the parasitoid. Biology of the Cell 1995, 83:I-I3.

30. Galibert L, Rocher J, Ravallec M, Duonor-Cerutti M, Webb BA, Volkoff AN: Two Hyposoter didymator ichnovirus genes expressed in the lepidopteran host encode secreted or membrane-associated serine and threonine rich proteins in segments that may be nested. I Insect Physiol 2003, 49(5):44|-45।.

3I. Volkoff AN, Beliveau C, Rocher J, Hilgarth R, Levasseur A, DuonorCerutti M, Cusson M, Webb BA: Evidence for a conserved polydnavirus gene family: ichnovirus homologs of the CsIV repeat element genes. Virology 2002, 300(2):316-33I.

32. Volkoff AN, Cerutti P, Rocher J, Ohresser MC, Devauchelle G, Duonor-Cerutti M: Related RNAs in lepidopteran cells after in vitro infection with Hyposoter didymator virus define a new polydnavirus gene family. Virology 1999, 263(2):349-363.

33. Volkoff AN, Rocher J, Cerutti P, Ohresser MC, d'Aubenton-Carafa Y, Devauchelle G, Duonor-Cerutti M: Persistent expression of a newly characterized Hyposoter didymator polydnavirus gene in long-term infected lepidopteran cell lines. J Gen Virol 2001, 82(Pt 4):963-969.

34. Amaya KE, Asgari S, Jung R, Hongskula M, Beckage NE: Parasitization of Manduca sexta larvae by the parasitoid wasp Cotesia congregata induces an impaired host immune response. Insect Physiol 2005, 5 I (5):505-5 I 2

35. Turnbull MW, Martin SB, Webb BA: Quantitative analysis of hemocyte morphological abnormalities associated with Campoletis sonorensis parasitization. J Insect Sci 2004, 4: I I

36. Asgari S: Venom proteins from polydnavirus-producing endoparasitoids: their role in host-parasite interactions. Arch Insect Biochem Physiol 2006, 6 I (3): 146-156.

37. Bae S, Kim Y: Host physiological changes due to parasitism of a braconid wasp, Cotesia plutellae, on diamondback moth, Plutella xylostella. Comp Biochem Physiol A Mol Integr Physiol 2004, I38(I):39-44. 
38. Beckage NE: Modulation of immune responses to parasitoids by polydnaviruses. Parasitology 1998, I I 6(Suppl):S57-64.

39. Shelby KS, Adeyeye OA, Okot-Kotber BM, Webb BA: Parasitismlinked block of host plasma melanization. I Invertebr Pathol 2000, 75(3):218-225.

40. Shelby KS, Webb BA: Polydnavirus-mediated suppression of insect immunity. I Insect Physiol 1999, 45(5):507-5 I4.

41. Stoltz DB, Cook DI: Inhibition of host phenoloxydase activity by parasitoid hymenoptera. Experientia 1983, 39:1022-1024.

42. Cerenius L, Soderhall K: The prophenoloxidase-activating system in invertebrates. Immunol Rev 2004, 198: I 16-126.

43. Espagne E, Dupuy C, Huguet E, Cattolico L, Provost B, Martins N, Poirie M, Periquet G, Drezen JM: Genome sequence of a polydnavirus: insights into symbiotic virus evolution. Science 2004 , 306(5694):286-289.

44. Kroemer JA, Webb BA: Polydnavirus genes and genomes: emerging gene families and new insights into polydnavirus replication. Annu Rev Entomol 2004, 49:43I-456.

45. Webb BA, Strand MR, Dickey SE, Beck MH, Hilgarth RS, Barney WE, Kadash K, Kroemer JA, Lindstrom KG, Rattanadechakul W, Shelby KS, Thoetkiattikul H, Turnbull MW, Witherell RA: Polydnavirus genomes reflect their dual roles as mutualists and pathogens. Virology 2006, 347(I): I60-174

46. Kroemer JA, Webb BA: Ikappabeta-related vankyrin genes in the Campoletis sonorensis ichnovirus: temporal and tissuespecific patterns of expression in parasitized Heliothis virescens lepidopteran hosts. J Virol 2005, 79(1 2):7617-7628.

47. Thoetkiattikul H, Beck MH, Strand MR: Inhibitor kappaB-like proteins from a polydnavirus inhibit NF-kappaB activation and suppress the insect immune response. Proc Natl Acad Sci U S A 2005, I 02(32): I |426-I |43I.

48. Turnbull MW, Volkoff AN, Webb BA, Phelan P: Functional gap junction genes are encoded by insect viruses. Curr Biol 2005 I 5(13): R491-492.

49. Asgari S, Schmidt O: Isolation of an imaginal disc growth factor homologue from Pieris rapae and its expression following parasitization by Cotesia rubecula. I Insect Physiol 2004, 50(8):687-694.

50. Consoli FL, Brandt SL, Coudron TA, Vinson SB: Host regulation and release of parasitism-specific proteins in the system Toxoneuron nigriceps-Heliothis virescens. Comp Biochem Physiol B Biochem Mol Biol 2005, I 42(2): I8I - I9I.

5I. Dong K, Zhang D, Dahlman DL: Down-regulation of juvenile hormone esterase and arylphorin production in Heliothis virescens larvae parasitized by Microplitis croceipes. Archives of Insect Biochemistry and Physiology 1996, 32(2):237-248

52. Kim $Y$ : Identification of host translation inhibitory factor of Campoletis sonorensis ichnovirus on the tobacco budworm, Heliothis virescens. Arch Insect Biochem Physiol 2005, 59(4):230-244.

53. Shelby KS, Cui L, Webb BA: Polydnavirus-mediated inhibition of lysozyme gene expression and the antibacterial response. Insect Mol Biol 1998, 7(3):265-272.

54. Shelby KS, Webb BA: Polydnavirus infection inhibits synthesis of an insect plasma protein, arylphorin. J Gen Virol 1994, 75(Pt 9):2285-2292

55. Shelby KS, Webb BA: Polydnavirus infection inhibits translation of specific growth-associated host proteins. Insect Biochem Mol Biol 1997, 27(3):263-270.

56. De Gregorio E, Spellman PT, Rubin GM, Lemaitre B: Genome-wide analysis of the Drosophila immune response by using oligonucleotide microarrays. Proc Natl Acad Sci U S A 200I, 98(22): $12590-12595$

57. Johansson KC, Metzendorf C, Soderhall K: Microarray analysis of immune challenged Drosophila hemocytes. Exp Cell Res 2005, 305(I): 145-155

58. Aguilar R, Jedlicka AE, Mintz M, Mahairaki V, Scott AL, Dimopoulos $\mathrm{G}$ : Global gene expression analysis of Anopheles gambiae responses to microbial challenge. Insect Biochem Mol Biol 2005 35(7):709-7| 9.

59. Wertheim B, Kraaijeveld AR, Schuster E, Blanc E, Hopkins M, Pletcher SD, Strand MR, Partridge L, Godfray HC: Genome-wide gene expression in response to parasitoid attack in Drosophila. Genome Biol 2005, 6(II):R94.

60. Dimopoulos G, Christophides GK, Meister S, Schultz J, White KP, Barillas-Mury C, Kafatos FC: Genome expression analysis of
Anopheles gambiae: responses to injury, bacterial challenge, and malaria infection. Proc Natl Acad Sci U S A 2002, 99(13):88|4-88|9.

61. [http://bioweb.ensam.inra.fr/spodobase/].

62. Bergoin M, Tijssen P: Biological and molecular properties of Densoviruses and their use in protein expression and biological control. Plenum Press, New-York and London;; 1998.

63. Bachali S, Jager M, Hassanin A, Schoentgen F, Jolles P, Fiala-Medioni A, Deutsch JS: Phylogenetic analysis of invertebrate lysozymes and the evolution of lysozyme function. J Mol Evol 2002, 54(5):652-664.

64. Gorman MJ, Kankanala P, Kanost MR: Bacterial challenge stimulates innate immune responses in extra-embryonic tissues of tobacco hornworm eggs. Insect Mol Biol 2004, I3(1): 19-24.

65. Sun SC, Asling B, Faye I: Organization and expression of the immunoresponsive lysozyme gene in the giant silk moth, Hyalophora cecropia. J Biol Chem I99I, 266(I 0):6644-6649.

66. Jiang $\mathrm{H}$, Wang $\mathrm{Y}$, Kanost MR: Pro-phenol oxidase activating proteinase from an insect, Manduca sexta: a bacteria-inducible protein similar to Drosophila easter. Proc Natl Acad Sci U S A 1998, 95(2I): 12220-12225.

67. Jiang $H$, Kanost MR: The clip-domain family of serine proteinases in arthropods. Insect Biochem Mol Biol 2000, 30(2):95- 05.

68. Zou Z, Wang Y, Jiang H: Manduca sexta prophenoloxidase activating proteinase-I (PAP-I) gene: organization, expression, and regulation by immune and hormonal signals. Insect Biochem Mol Biol 2005, 35(6):627-636.

69. Yu XQ, Kanost MR: Immulectin-2, a lipopolysaccharide-specific lectin from an insect, Manduca sexta, is induced in response to gram-negative bacteria. I Biol Chem 2000, 275(48):37373-3738।

70. Koizumi N, Imamura M, Kadotani T, Yaoi K, Iwahana H, Sato R: The lipopolysaccharide-binding protein participating in hemocyte nodule formation in the silkworm Bombyx mori is a novel member of the C-type lectin superfamily with two different tandem carbohydrate-recognition domains. FEBS Lett 1999, 443(2): 139-143.

7I. Ling E, Yu XQ: Cellular encapsulation and melanization are enhanced by immulectins, pattern recognition receptors from the tobacco hornworm Manduca sexta. Dev Comp Immunol 2006, 30(3):289-299.

72. Yu XQ, Tracy ME, Ling E, Scholz FR, Trenczek T: A novel C-type immulectin-3 from Manduca sexta is translocated from hemolymph into the cytoplasm of hemocytes. Insect Biochem Mol Biol 2005, 35(4):285-295.

73. Zhu Y, Johnson TJ, Myers AA, Kanost MR: Identification by subtractive suppression hybridization of bacteria-induced genes expressed in Manduca sexta fat body. Insect Biochem Mol Biol 2003, 33(5):54I-559.

74. Nakhasi HL, Pogue GP, Duncan RC, Joshi M, Atreya CD, Lee NS, Dwyer DM: Implications of calreticulin function in parasite biology. Parasitology Today 1998, 14(4):157-160.

75. Gelebart P, Opas M, Michalak M: Calreticulin, a Ca2+-binding chaperone of the endoplasmic reticulum. Int J Biochem Cell Biol 2005, 37(2):260-266.

76. Johnson S, Michalak M, Opas M, Eggleton P. The ins and outs of calreticulin: from the ER lumen to the extracellular space. Trends Cell Biol 200I, I I(3): I22-129.

77. Gardai SJ, McPhillips KA, Frasch SC, Janssen WJ, Starefeldt A, Murphy-Ullrich JE, Bratton DL, Oldenborg PA, Michalak M, Henson PM: Cell-surface calreticulin initiates clearance of viable or apoptotic cells through trans-activation of LRP on the phagocyte. Cell 2005, I 23(2):32I-334

78. Choi JY, Whitten MM, Cho MY, Lee KY, Kim MS, Ratcliffe NA, Lee $B L:$ Calreticulin enriched as an early-stage encapsulation protein in wax moth Galleria mellonella larvae. Dev Comp Immunol 2002, 26(4):335-343.

79. Asgari $S$, Schmidt $O$ : Is cell surface calreticulin involved in phagocytosis by insect hemocytes? J Insect Physiol 2003, 49(6):545-550.

80. Zhang G, Schmidt $O$, Asgari S: A calreticulin-like protein from endoparasitoid venom fluid is involved in host hemocyte inactivation. Dev Comp Immunol 2005.

8I. Ramet M, Pearson A, Manfruelli P, Li X, Koziel H, Gobel V, Chung E, Krieger M, Ezekowitz RA: Drosophila scavenger receptor $\mathrm{Cl}$ is 
a pattern recognition receptor for bacteria. Immunity 200I, 15(6): 1027-1038.

82. Costa SC, Ribeiro C, Girard PA, Zumbihl R, Brehelin M: Modes of phagocytosis of Gram-positive and Gram-negative bacteria by Spodoptera littoralis granular haemocytes. J Insect Physiol 2005, 5 I (I):39-46.

83. Lazzaro BP: Elevated polymorphism and divergence in the class $C$ scavenger receptors of Drosophila melanogaster and D. simulans. Genetics 2005, I69(4):2023-2034

84. Niki I, Yokokura H, Sudo T, Kato M, Hidaka H: Ca2+ signaling and intracellular Ca2+ binding proteins. J Biochem (Tokyo) 1996, 120(4):685-698.

85. Kotani E, Yamakawa M, Iwamoto S, Tashiro M, Mori H, Sumida M, Matsubara F, Taniai K, Kadono-Okuda K, Kato Y, Mori H: Cloning and expression of the gene of hemocytin, an insect humora lectin which is homologous with the mammalian von Willebrand factor. Biochim Biophys Acta 1995, I 260(3):245-258.

86. Cooper DN: Galectinomics: finding themes in complexity. Biochim Biophys Acta 2002, I 572(2-3):209-23I.

87. Hughes RC: Galectins as modulators of cell adhesion. Biochimie 200I, 83(7):667-676.

88. Liu FT, Patterson RJ, Wang JL: Intracellular functions of galectins. Biochim Biophys Acta 2002, I 572(2-3):263-273.

89. Pace KE, Baum LG: Insect galectins: roles in immunity and development. Glycoconj J 2004, I 9(7-9):607-614.

90. Christophides GK, Vlachou D, Kafatos FC: Comparative and functional genomics of the innate immune system in the malaria vector Anopheles gambiae. Immunol Rev 2004, 198: | 27- 148.

91. Lavine MD, Beckage NE: Polydnaviruses: potent mediators of host insect immune dysfunction. Parasitol Today 1995, II (I0):368-378

92. Le NT, Asgari S, Amaya K, Tan FF, Beckage NE: Persistence and expression of Cotesia congregata polydnavirus in host larvae of the tobacco hornworm, Manduca sexta. J Insect Physiol 2003, 49(5):533-543.

93. Leclerc V, Pelte N, El Chamy L, Martinelli C, Ligoxygakis P, Hoffmann JA, Reichhart JM: Prophenoloxidase activation is not required for survival to microbial infections in Drosophila. EMBO Rep 2006, 7(2):231-235

94. Huang LH, Christensen BM, Chen CC: Molecular cloning of a second prophenoloxidase cDNA from the mosquito Armigeres subalbatus: prophenoloxidase expression in blood-fed and microfilariae-inoculated mosquitoes. Insect Mol Biol 200I, I 0(I):87-96

95. Rajagopal R, Thamilarasi K, Venkatesh GR, Srinivas P, Bhatnagar RK Immune cascade of Spodoptera litura: cloning, expression, and characterization of inducible prophenol oxidase. Biochem Biophys Res Commun 2005, 337(I ):394-400.

96. Strand MR, Pech LL: Microplitis demolitor polydnavirus induces apoptosis of a specific haemocyte morphotype in Pseudoplusia includens. J Gen Virol 1995, 76(Pt 2):283-291.

97. Beckage NE, Tan FF, Schleifer KW, Lane RD, Cherubin LL: Characterization and biological effects of Cotesia congregata polydnavirus on host larvae of the tobacco hornworm, Manduca sexta. Arch Insect Biochem Physiol 1994, 26: I65-195.

98. Matsumoto $Y$, Oda $Y$, Uryu M, Hayakawa $Y$ : Insect cytokine growth-blocking peptide triggers a termination system of cellular immunity by inducing its binding protein. J Biol Chem 2003, 278(40):38579-38585.

99. Strand MR, Hayakawa Y, Clark KD: Plasmatocyte spreading peptide (PSPI) and growth blocking peptide (GBP) are multifunctional homologs. J Insect Physiol 2000, 46(5):817-824.

100. Irving P, Ubeda JM, Doucet D, Troxler L, Lagueux M, Zachary D, Hoffmann JA, Hetru C, Meister M: New insights into Drosophila larval haemocyte functions through genome-wide analysis. Cell Microbiol 2005, 7(3):335-350.

10I. Negre V, Hotelier T, Volkoff A-N, Gimenez S, Cousserans F, Mita K, Sabau X, Rocher J, López-Ferber M, d'Alençon E, Audant P, Sabourault $C$, Bidegainberry V, Hilliou F, Fournier P: SPODOBASE : an EST database for the lepidopteran crop pest Spodoptera. $B M C$ Bioinformatics in press.

102. Hugot K, Riviere MP, Moreilhon C, Dayem MA, Cozzitorto J, Arbio G, Barbry P, Weiss C, Galiana E: Coordinated regulation of genes for secretion in tobacco at late developmental stages: association with resistance against oomycetes. Plant Physiol 2004 134(2):858-870.
103. Rivers CF, Longworth JF: A non-occluded virus of Junonia coenia (Nymphalidae : Lepidotera). Journal of Invertebrate Pathology 1972, 20:369-370.

104. [http://www.prontosystems.com/]

105. [http://cardioserve.nantes.inserm.fr/mad/madscan/]

106. Yang YH, Dudoit S, Luu P, Lin DM, Peng V, Ngai J, Speed TP: Normalization for cDNA microarray data: a robust composite method addressing single and multiple slide systematic variation. Nucleic Acids Res 2002, 30(4): I 5.

107. Le Meur N, Lamirault G, Bihouee A, Steenman M, Bedrine-Ferran H, Teusan R, Ramstein G, Leger JJ: A dynamic, web-accessible resource to process raw microarray scan data into consolidated gene expression values: importance of replication. Nucleic Acids Res 2004, 32( 18):5349-5358.

108. [http://www-stat.stanford.edu/ tibs/SAM/].

109. Didier G, Brezellec P, Remy E, Henaut A: GeneANOVA - gene expression analysis of variance. Bioinformatics 2002 18(3):490-49|.

110. Tusher VG, Tibshirani R, Chu G: Significance analysis of microarrays applied to the ionizing radiation response. Proc Nat Acad Sci U S A 200I, 98(9):5II6-5I2I.

III. Yang IV, Chen E, Hasseman JP, Liang W, Frank BC, Wang S, Sharov V, Saeed Al, White J, Li J, Lee NH, Yeatman T], Quackenbush J: Within the fold: assessing differential expression measures and reproducibility in microarray assays. Genome Biol 2002, 3(I I):research0062.

112. Ramakers C, Ruijter JM, Deprez RH, Moorman AF: Assumptionfree analysis of quantitative real-time polymerase chain reaction (PCR) data. Neurosci Lett 2003, 339(I):62-66

1 13. Vandesompele J, De Preter K, Pattyn F, Poppe B, Van Roy N, De Paepe A, Speleman F: Accurate normalization of real-time quantitative RT-PCR data by geometric averaging of multiple internal control genes. Genome Biol 2002, 3(7):RESEARCH0034.

I I4. Shida K, Terajima D, Uchino R, Ikawa S, Ikeda M, Asano K, Watanabe T, Azumi K, Nonaka M, Satou Y, Satoh N, Satake M, Kawazoe Y, Kasuya $A$ : Hemocytes of Ciona intestinalis express multiple genes involved in innate immune host defense. Biochem Biophys Res Commun 2003, 302(2):207-2I8.

II5. Schmit AR, Ratcliffe NA: The encapsulation of foreign tissue implants in Galleria mellonella larvae. J Insect Physiol 1977, 23(2): $175-184$

Publish with Biomed Central and every scientist can read your work free of charge

"BioMed Central will be the most significant development for disseminating the results of biomedical research in our lifetime. "

Sir Paul Nurse, Cancer Research UK

Your research papers will be:

- available free of charge to the entire biomedical community

- peer reviewed and published immediately upon acceptance

- cited in PubMed and archived on PubMed Central

- yours - you keep the copyright
BioMedcentral 